\title{
A 3-D Model of the Crust and Uppermost Mantle Beneath the Central and Western US by Joint Inversion of Receiver Functions and Surface Wave Dispersion
}

\author{
Weisen Shen ${ }^{1}$, Michael H. Ritzwoller ${ }^{1}$, and Vera Schulte-Pelkum ${ }^{2}$ \\ 1- Department of Physics, University of Colorado at Boulder, Boulder, CO 80309-0390 \\ 2 - Cooperative Institute for Research in Environmental Sciences and Department of \\ Geological Sciences, University of Colorado at Boulder, Boulder, CO 80309-0390
}

Rayleigh wave phase velocity maps from ambient noise and earthquake data are inverted jointly with receiver functions observed at 828 stations from the USArray Transportable Array west of $100^{\circ} \mathrm{W}$ longitude for data recorded in the years 2005 through 2010 to produce a 3-D model of shear wave speeds beneath the central and western US to a depth of $150 \mathrm{~km}$. Eikonal tomography is applied to ambient noise data to produce about 300000 Rayleigh wave phase speed curves and Helmholtz tomography is applied to data following $1550(\mathrm{Ms}>5.0)$ earthquakes so that Rayleigh wave dispersion maps are constructed from $8 \mathrm{sec}$ to $80 \mathrm{sec}$ period with associated uncertainties across the region. Harmonic stripping generates back-azimuth independent receiver functions with uncertainty estimates for each of the stations. A non-linear Bayesian Monte-Carlo method is used to estimate a distribution of Vs models beneath each station by jointly interpreting surface wave dispersion and receiver functions and their uncertainties. The assimilation of receiver functions improves the vertical resolution of the model by reducing the range of estimated Moho depths, improving the determination of the shear velocity jump across Moho, and improving the resolution of the depth of anomalies in the uppermost mantle. A great variety of geological and tectonic features are revealed in the 3-D model and call for more detailed local to regional scale analysis and interpretation. 


\section{Introduction}

Continental-scale arrays of seismometers with inter-station spacings between 50 and $100 \mathrm{~km}$ such as the EarthScope USArray Transportable Array (TA), the Chinese Earthquake Array, the Virtual European Broadband Seismic Network, or for that matter PASSCAL or USArray Flexible Array experiments that in some cases comprise more than 100 instruments, provide ideal data for surface wave tomography. The combination of ambient noise measurements, typically between about 8 and $40 \mathrm{sec}$ period (e.g., in the US: Shapiro et al., 2005; Moschetti et al., 2007; Lin et al., 2008; Bensen et al., 2008), and earthquake-derived measurements, from about 25 to $100 \mathrm{sec}$ period (e.g., in the US: Pollitz, 2008; Lin et al., 2009, Lin and Ritzwoller, 2011a), produces broadband dispersion maps that constrain earth structure homogeneously through the crust to a depth of about $150 \mathrm{~km}$ in the uppermost mantle. Such broad-band measurements from ambient noise and/or earthquake data observed with USArray have been used by Yang et al. (2008), Pollitz and Snoke (2010), Moschetti et al. (2010a,b), Lin et al. (2010), Obrebski et al. (2011), and others to produce 3-D shear velocity models of the crust and uppermost mantle in the western US.

The use of surface wave dispersion data alone to produce models of the crust and uppermost mantle, however, presents significant non-uniqueness problems (e.g., Shapiro et al., 2002) because surface waves do not constrain the strength or location of jumps in shear velocity. Receiver functions, in contrast, provide the spatially discrete local response of seismic waves to discontinuities beneath receiver locations (Langston, 1979). As a consequence, combining surface wave data with receiver function data has been a natural direction for research and was introduced more than a decade ago (e.g., Last et al. 1997, Ozalaybey et al., 1997), with numerous realizations of the idea subsequently having been developed. In particular, joint inversions of receiver functions and surface wave dispersion within the context of non-linear, model-space sampling schemes have been developed in recent years (e.g., Chang et al., 2004; Lawrence and Wiens, 2004; Liu et al., 2010; Tokam et al., 2010; Bodin et al., 2011; Shen et al., 2012). 
Shen et al. (2012) presents a non-linear Bayesian Monte-Carlo method to estimate a Vs model with uncertainties beneath stations by jointly interpreting surface wave dispersion and receiver functions and associated uncertainties. This method is designed for automated application to large arrays of broadband seismometers. Here, we apply this method to the joint inversion of surface wave dispersion maps and receiver functions with observations taken from 828 stations of the USArray Transportable Array (TA) as well as USArray reference network stations. The region of study extends to $100^{\circ} \mathrm{W}$ longitude and covers the entire western US including parts of the Great Plains extending about $1000 \mathrm{~km}$ eastward from earlier studies (Yang et al., 2008; Moschetti et al., 2010a,b), and includes data acquired through the year 2010, adding more than two years of TA data compared to these earlier studies. Significantly, as discussed here, the introduction of receiver functions into the inversion with surface wave dispersion data from ambient noise and earthquake data significantly improves the vertical resolution of the model, revealing higher fidelity images of the crust and uppermost mantle across nearly half of the US.

\section{Generation of the 3-D Model by Joint Inversion}

Rayleigh wave phase velocity measurements from 8 to $40 \mathrm{sec}$ period were acquired from ambient noise using USArray TA stations from the beginning of 2005 until the end of 2010. The data processing procedures described by Bensen et al. (2007) and Lin et al. (2008) were used to produce nearly 300000 dispersion curves between the 828 TA stations west of $100^{\circ} \mathrm{W}$ longitude and USArray backbone (or reference network) stations. Eikonal tomography (Lin et al., 2009) produced Rayleigh wave phase velocity maps for ambient noise from 8 to $40 \mathrm{sec}$ period (e.g., Fig. 1a,b). Eikonal tomography is a geometrical ray theoretic technique that models off-great-circle propagation but not finite frequency effects (e.g., wavefront healing, back-scattering, etc.). Rayleigh wave phase velocity measurements from 25 to $80 \mathrm{sec}$ period were obtained following earthquakes using the Helmholtz tomography method (Lin and Ritzwoller, 2011), also applied to TA data from 2005 through 2010. Examples are shown in Figure 1c,e,f. A total of 1550 earthquakes were used with magnitude $\mathrm{M}_{\mathrm{s}}>5.0$, of which on average about 270 earthquakes supplied measurements at each location. Helmholtz tomography is a finite 
frequency method that accounts for wavefield complexities that affect longer period surface waves, but Lin and Ritzwoller (2011) and Ritzwoller et al. (2011) argue that below about $40 \mathrm{sec}$ period such corrections are not required.

Ambient noise and earthquake phase velocity maps overlap between 25 and $40 \mathrm{sec}$ period. In the period band of overlap, the two measurements are averaged at each location based on their uncertainties. Uncertainties in Rayleigh wave dispersion maps derived from ambient noise average about $15 \mathrm{~m} / \mathrm{s}$ between periods of 10 and $25 \mathrm{sec}$, and uncertainties of earthquake-derived maps also average about $15 \mathrm{~m} / \mathrm{s}$ but between 30 and $60 \mathrm{sec}$ period. At periods shorter and longer than those cited, uncertainties in each type of measurement grow. Therefore, the uncertainty of the combined measurements is approximately flat, on average, at $15 \mathrm{~m} / \mathrm{s}$ from 10 to $60 \mathrm{sec}$ period, but grows at shorter and longer periods. An example of a dispersion curve with error bars at a point in the Basin and Range province is shown in Figure 2a. In the period band of overlap, the ambient noise and earthquake-derived maps agree very well, as Figure 1b,c,d illustrates for the $30 \mathrm{sec}$ maps. The rms difference between the maps is $20 \mathrm{~m} / \mathrm{s}$, consistent with the estimated uncertainty $(\sim 15 \mathrm{~m} / \mathrm{s})$ for the $30 \mathrm{sec}$ maps.

Receiver functions are constructed at each of the $828 \mathrm{TA}$ stations west of $100^{\circ} \mathrm{W}$ longitude using the method described by Shen et al. (2012). These are exclusively Pwave receiver functions constructed for each station individually based on the timedomain iterative deconvolution method (Ligorria and Ammon, 1999). Earthquakes are used if they occur between $30^{\circ}-90^{\circ}$ from the station with $\mathrm{m}_{\mathrm{b}}>5.0$ during the lifetime of the station deployment. An azimuthally independent receiver function, $\mathrm{R}_{0}(\mathrm{t})$, for each station is computed by fitting a truncated Fourier Series at each time over azimuth and stripping the azimuthally variable terms using a method referred to as harmonic stripping (Shen et al., 2012) which exploits the azimuthal harmonic behavior in receiver functions (e.g., Girardin and Farra,1998; Bianchi et al., 2010). The rms of the azimuthally variable terms at each time is taken as the $1 \sigma$ uncertainty at that time. An example for a station in the Basin and Range province is shown in Figure $2 b$ as a pair of locally parallel black lines, which delineate the uncertainty at each time. Shen et al. (2012) describes 
procedures to assess and guarantee the quality of the RFs. On average, about 130 earthquakes satisfy the quality control provisions for each station.

For simplicity, we seek models that have no more vertical structure than required to fit the data within a tolerance specified by the data uncertainties. There is one sedimentary layer with a linear velocity gradient with depth. Three parameters are used to describe this layer: layer thickness and Vsv at the top and bottom of the layer. There is one crystalline crustal layer described by five parameters: layer thickness $(\mathrm{km})$ and four B-splines for Vsv. Finally there is one upper-most mantle layer to a depth of $200 \mathrm{~km}$ described by five B-splines for Vsv. The smoothness of the model is imposed by the parameterization so that ad hoc damping is not needed during the inversion. Because only Rayleigh waves are used, there is predominant sensitivity to Vsv and we assume an isotropic Vsv model where $\mathrm{Vs}=\mathrm{Vsh}=\mathrm{Vsv}$. We set the $\mathrm{Vp} / \mathrm{Vs}$ ratio to 2.0 in the sedimentary layer and 1.75 in the crystalline crust and mantle. For density we use the scaling relation advocated by Christensen and Mooney (1995) in the crust and by Karato (1994) in the mantle. We also apply a physical dispersion correction (Kanamori and Anderson, 1977) using the Q model from PREM (Dziewonski \& Anderson, 1981). All models are reduced to $1 \mathrm{sec}$ period and are defined relative to a reference model (Shapiro and Ritzwoller, 2002) subject to allowed perturbations (presented in Table 1 of Shen et al., 2012) and model constraints. Constraints are that models are continuous between discontinuities at the base of the sediments and Moho, continuous in the mantle, and velocity increases linearly with depth in the sedimentary layer and monotonically with depth in the crystalline crust. The velocity contrasts across the sedimentary basement and across the Moho discontinuity are positive and Vs $<4.9 \mathrm{~km} / \mathrm{s}$ throughout the model.

The Bayesian Monte Carlo joint inversion method described by Shen et al. (2012) constructs a prior distribution of models at each location defined by allowed perturbations relative to the reference model as well as model constraints. The principal output is the posterior distribution of models that satisfy the receiver function and surface wave dispersion data within tolerances that depend on data uncertainties. The statistical properties of the posterior distribution quantify model errors. Examples of prior and posterior distributions for the inversion based on surface wave data alone are shown in 
Figure 3a-c, which illustrates that surface wave data alone do not constrain well crustal thickness or the jump in Vs across Moho but do determine Vs between discontinuities. In contrast, when receiver functions (e.g., Fig. 2b) and surface wave dispersion data (e.g., Fig. 2a) are applied jointly crustal thickness and the Vs jump across Moho are much more tightly constrained (Fig. 3d-f).

The details depend on the nature of the receiver function, but in general the vertical discontinuity structure of the crust is clarified and the vertical resolution of the model is improved by introducing receiver functions into the inversion with surface wave dispersion data. Figure 2c, d presents examples of model ensembles for a point in the Basin and Range province based on surface wave data alone compared with surface wave and receiver function data used jointly. Consistent with the observations of the marginal distributions shown in Figure 3, the introduction of receiver functions sharpens the image around the Moho, which reduces the trade-off between model variables in the lower crust and uppermost mantle, clarifying the thickness of the crust, the jump in Vs across the Moho, and reducing the spread of model velocities in the mantle.

Examples at other locations of data and resulting ensembles of models are presented by Shen et al. (2012) (in the Denver Basin, the Colorado Plateau, the Great Plains) and in Figures 4 and 5 here for a variety of geological settings. The receiver functions in Figure 4a-e are typical and well-behaved in that the azimuthal variability is relatively small so that the uncertainties are small enough that the azimuthally independent receiver function is well-defined. At these locations the surface waves and receiver functions can be fit well simultaneously and the introduction of receiver functions reduces the extent of the ensemble of accepted models, which are presented in Figure 5a-e. In some locations, however, the receiver function is dominated by azimuthal variability so that uncertainties are very large. An example is seen in Figure $4 \mathrm{f}$ for a station in the Basin and Range province. For this station lateral heterogeneity is large enough to vitiate the azimuthally independent receiver function and the joint inversion reverts principally to fitting the surface wave data alone. As a consequence, the ensemble of models is broad around the Moho (Fig. 5f). Such problems with receiver functions are relatively rare and appear mostly at discrete points. For most of the Basin and Range province receiver functions 
are quite well-behaved (e.g., Fig. 2b). The principal exception is the sedimentary basins of southeastern Wyoming and northern Colorado, which produce sufficiently complex receiver functions that our simple model parameterization cannot fit well. However, these problems are accounted for in the error analysis and they are reflected in model uncertainties.

Surface wave data are fit acceptably in the joint inversion except near the far western periphery of the region where dispersion maps from ambient noise and earthquake tomography are most different in the period band of overlap. In total, 817 out of the 829 stations have a surface wave reduced chi-squared value $\chi_{\text {min }}^{2}<1$. Receiver functions are also usually well fit in the joint inversion such that 808 stations have a reduced chisquared value $\chi_{\text {min }}^{2}<1$. The stations with larger receiver function misfit are principally in southwestern Wyoming and the northern edge of the Colorado Plateau due to complexity of the sedimentary basin structure that is incompletely modeled by our simple sedimentary parameterization. There are also several isolated stations near structural boundaries (e.g., in the Basin and Range province, Fig. 4f) where an azimuthally independent receiver function could not be well determined.

\section{Discussion}

The joint inversion is performed at the locations of the TA stations, producing an irregularly spaced mosaic of distributions of 1-D models separated, on average, by about $70 \mathrm{~km}$. An example for the model at $120 \mathrm{~km}$ depth is shown in Figure 6a. At each depth, simple-kriging is applied to interpolate the models onto a $0.5^{\circ} \times 0.5^{\circ}$ grid as seen in Figure 6b. Views of averages of the distributions of accepted models are presented in Figures 6b, 7,9 , and 11 .

\subsection{Features of the 3-D model}

The upper crustal part of the model is dominated by the existence or absence of sediments. The low velocity features in Figure $7 \mathrm{a}$ are located at the major sedimentary basins of the central and western US, including the Central (or Great) Valley of California, the Pasco basin in Washington, most prominently the Wyoming-Utah-Idaho thrust belt covering southwestern Wyoming, the Powder River basin in northeast 
Wyoming, the Williston basin in North Dakota and eastern Montana, the Denver basin in northeast Colorado, and parts of the Permian and Anadarko basins near the edge of the map in Texas. The velocity anomaly of the Pasco basin is weaker than the others because of capping or interlayering with basalt flows. The sedimentary parameterization is quite simple and inaccuracies in the resulting sedimentary model may cause low velocities to leak into the upper crystalline crust, but no deeper. Sediments are not prominent features of the vertical profiles presented in Figure 11, but do appear clearly beneath the Central Valley of California in profiles B-B' and D-D'. High upper crustal velocities in Figure 7a, reflecting the lack of sediments, are correlated principally with mountain ranges; e.g., the Rocky Mountain cordillera, the Colorado Plateau, the eastern and southern Basin and Range province, and the Sierra Nevada.

The predominant large-scale feature that appears in the lower crust (Fig. $7 \mathrm{~b}$ ) is the dichotomy between the high shear wave speeds in the Great Plains east of the Rocky Mountain front and the generally lower wave speeds in the tectonically deformed west. High lower crustal velocities in the west are associated with Pasco basin intrusives of the Columbia River flood basalt province, the Wyoming craton, and the interior (particular the northern interior) of the Colorado Plateau. Relative high velocities are found beneath the Snake River Plain. These high lower crustal velocities in the western US may be compositional in origin, reflecting either past volcanism or the presence of Archean blocks. A likely cause for fast lower crust under the Columbia Plateau and Snake River Plain is a mafic underplate associated with basaltic magmatism. Low velocities in the lower crust are found prominently in the southern Basin and Range province, on the western and southern peripheries of the Colorado Plateau, and in coastal California north of Cape Mendocino. Fast lower crustal velocities appear conspicuously in the Great Plains on the vertical profiles of Figure 11, but also strikingly beneath the Colorado Plateau (A-A', D-D'). The persistence of high-velocity, presumably strong lower crust under the Laramide-affected Wyoming craton and the Colorado Plateau suggests that crustal strength may influence surface deformation. In contrast, the lower crustal velocity contrast tracking the Rocky Mountain deformation front and Rio Grande Rift truncates much older Proterozoic mafic lower crust (the "7.xx layer" seen by Gorman et al., 2002 in Wyoming and Montana and the granite-rhyolite province lower crustal restite proposed 
by Karlstrom et al., 2005) to the east, and cuts across the general NE-SW trend inherited from continental assembly (Whitmeyer and Karlstrom, 2007).

Crustal thickness and the jump in shear velocity across the Moho, two of the variables most improved by the introduction of receiver function waveforms in the inversion, are presented in Figures 9a,b. To first order, crustal thickness agrees with similar estimates made by Gilbert (2012) using receiver functions alone, except in regions where the Moho converted arrival, which provides information about crustal thickness, is of very low amplitude or absent, such as beneath parts of the Colorado Plateau (Figs. 4e, 5e). Crustal thickness is not simply related to surface elevation; for example, there is little obvious difference between crustal thickness near the Rocky Mountain front with the Great Plains. However, the thickest crust is in the northern Colorado Rockies ( $\sim 60 \mathrm{~km})$, consistent with the regional receiver function analysis of Karlstrom et al. (2012) using a denser array. Thinnest crust is less than $25 \mathrm{~km}$ in the Salton Trough. Even across the Great Plains, crustal thickness varies appreciably, from about $42 \mathrm{~km}$ depth in northern Nebraska to about $55 \mathrm{~km}$ near the Montana-North Dakota border. Another example of thinned crust is observed near the boundary of Wyoming and Montana, which was also observed by Gilbert (2012).

Regions that have a low amplitude for the Moho converted arrival in the receiver function appear in Figure $9 \mathrm{~b}$ as small jumps in Vs across Moho, and are presented with warm colors. These regions include parts of the coastal Pacific Northwest of Oregon, the Sierra Nevada, the Snake River Plain, parts of Wyoming, and the Colorado Plateau. A relationship to lithospheric delaminations or mantle drips is possible, as proposed in the Southern Sierra Nevada (Zandt et al., 2004, Boyd et al., 2004) and the Colorado Plateau (Levander et al., 2011, Bailey et al., 2012), which are underlain by relatively fast uppermost mantle. However, a reduced Moho velocity contrast is also consistent with high-velocity lower crust, such as an eclogitic root under the western Sierra Nevada foothills (Frassetto et al., 2011) or a mafic underplate. Most of the Basin and Range province has a large contrast in Vs across the Moho, as do parts of the Rocky Mountains and the Great Plains. 
Low mantle velocities (Fig. 6, 7c) are generally correlated with lower crustal velocities across the region probably because of the continuity of thermal anomalies across the Moho. Principal exceptions are the Pasco basin in southern Washington, the Snake River Plain, and the southwestern Basin and Range adjacent to the Sierra Nevada, perhaps indicative of compositional heterogeneity in the crust caused by volcanic intrusives overlying hot mantle. The model in the mantle is resolved to scales of geological and tectonic relevance, and many features are observed on the vertical profiles of Figure 11 that are deserving of further detailed analysis and thermal modeling.

Examples on profile A-A' include the observation of low velocities in the supra-slab wedge beneath the Cascade Range, the Snake River Plain, the Basin and Range Province, and the Rio Grande Rift as well as high velocities beneath the Colorado Plateau. On profile B-B', the along hot spot track tilt of the low velocity anomaly underyling the Snake River Plain is seen as well as the rapid transition to high velocities beneath the Great Plains. The subducting Juan de Fuca slab appears on profile C-C' along with a resolved deep relative low velocity feature underlying the Black Hills of South Dakota. The mantle drip (Boyd et al., 2004; Zandt et al., 2004; Yang and Forsyth, 2006) underlying the Central Valley of California and the western Sierra Nevada is seen in profile D-D', along with low velocities beneath the Rio Grande Rift and the rapid transition to the Great Plains province in eastern New Mexico, which is consistent with previous studies (Wilson et al., 2002, Gao et al., 2004, West et al., 2004). The eastward down-tilted low anomaly beneath the Basin and Range/western Colorado Plateau may be related to the complex embedment of the previous flat-subducted Farallon slab. Profile EE' presents a south-north transect of the Basin and Range province illustrating relatively higher velocities directly underlying Moho that characterize parts of this province. Higher velocities underlie the Blue Mountains, consistent with body wave tomography (Hales et al., 2005) and dip northward with depth. Finally, profile F-F' presents a south-north transect of the Rio Grande Rift and Rocky Mountains, illustrating the much lower shear wave speeds underlying the rift, and the rapid transition to high velocity mantle across the Cheyenne belt at the edge of the Archean Wyoming craton. 
On average, the uppermost mantle structure is similar to previous models in the overlapping area (Yang and Ritzwoller, 2008; Moschetti et al., 2010), and is also similar to models constructed from surface wave/body wave tomography by Schmandt and Humphreys (2010) and Obrebski et al. (2011). However, the assimilation of receiver functions greatly improves the vertical resolution in the top $100 \mathrm{~km}$ of the model, whereas body wave tomography reveals much deeper structure.

\subsection{Model uncertainties}

One of the advantages of the Bayesian Monte Carlo method is that it provides uncertainties in the final model, determined from the standard deviation of the resulting marginal posterior distribution at each depth. Figures 6, 7,9 and 11 present averages of the distributions at each depth, examples of which are shown in Figure 3d-f. Figures 8 and 10 summarize the uncertainties at the depths and for crustal thickness and Vs jump across Moho shown in Figures 6, 7, and 9. Uncertainties in the upper crust average about $100 \mathrm{~m} / \mathrm{sec}$, with larger values near the Wyoming basins $(150-200 \mathrm{~m} / \mathrm{sec})$ due to the complexity of sedimentary structure there. Uncertainties also grow near the periphery of the maps because surface wave dispersion uncertainties increase there. In the lower crust, uncertainties are slightly smaller than in the upper crust but are still substantial due to remaining trade-offs with Moho depth and uppermost mantle velocities. The pattern of uncertainties at this depth, therefore, is correlated with the uncertainties in crustal thickness (Fig. 10a). At $60 \mathrm{~km}$ depth, uncertainties are much smaller than in the upper and lower crust, about $50 \mathrm{~m} / \mathrm{s}$ across much of the region, because this depth is separated from structural discontinuities across most of the region. In regions with thick crust, however, uncertainties increase to about $100 \mathrm{~m} / \mathrm{sec}$. At $120 \mathrm{~km}$ depth, uncertainties increase again because the structural sensitivity of surface waves decays with depth.

Figure 10c presents the spatial average of the standard deviation of these distributions across the study region for both the joint inversion and the inversion with surface wave data alone. The introduction of receiver functions reduces model uncertainties predominantly between depths of 35 and $50 \mathrm{~km}$, by introducing information about the depth to Moho and the velocity contrast across it. This uncertainty, represented as the spread of the distribution, however, does not include bias. In fact, relative to the earlier 
studies of Yang et al. (2008) and Moschetti et al. (2010a,b) the improvements actually extend to greater depths because to reduce the spread of models near Moho those studies imposed a positivity constraint on the velocity derivative with depth, which is not needed in the joint inversion. In some locations that constraint obscured the location in depth of the mantle anomalies and its removal further improves the vertical resolution of the model.

\section{Conclusions}

The joint use of ambient noise and earthquake data produces high resolution $(\sim 70$ $\mathrm{km}$ ) Rayleigh wave dispersion maps from about $8 \mathrm{sec}$ to $80 \mathrm{sec}$ period. Finite frequency effects should be accounted for at periods above about $40 \mathrm{sec}$ (Lin and Ritzwoller, 2011b) and are effected here through Helmholtz tomography (Lin and Ritzwoller, 2011a). Eikonal tomography (applied to ambient noise data) and Helmholtz tomography (applied to earthquake data) provide the uncertainty information needed to interpret the signals in ambient noise and earthquake maps quantitatively and reliably. In the frequency band of overlap between ambient noise and earthquake data, the ambient noise and earthquake derived phase velocity maps agree remarkably well.

Bayesian Monte Carlo inversions of the surface wave dispersion data alone reveal that shear wave speeds at depths well separated from first-order discontinuities (base of sediments, Moho) are well recovered by surface wave data alone. Near the discontinuities, however, trade-offs between the interface depths and adjacent shear wave speeds spread the ensemble of accepted models. Ad-hoc constraints introduced to reduce such trade-offs have other deleterious effects, such as causing mantle anomalies to move to different depths. The assimilation of receiver functions into the joint inversion with Rayleigh wave dispersion curves overcomes these difficulties, improving the vertical resolution of the model by reducing the range of estimated Moho depths, improving the determination of the shear velocity jump across Moho, and improving the resolution of the depth of anomalies in the uppermost mantle. The joint inversion produces a distribution of models beneath each station, which is summarized by the mean and standard deviation of the distribution at each depth. Across the vast majority of the region studied, the surface wave dispersion and receiver functions can be fit jointly with a very simple model 
parameterization, producing a smooth model between the two internal discontinuities. There are, however, details in the receiver functions, signals arriving more than 10 seconds after the direct $\mathrm{P}$-arrival, as well as azimuthal variations in the receiver functions that call for further refinement of the models with structures at greater depths or with anisotropy. But, these features are beyond the scope of the present study.

A great variety of geological and tectonic features are revealed in the 3-D model presented here and call for more detailed local to regional scale analysis and interpretation.

The 3-D model is useful as a basis for many other types of studies: studies of azimuthally/radially anisotropic structures, investigations of the density/thermal structure of the study region, and a starting model for other types of seismic investigations such as Common-Conversion Point stacking and body wave tomography (e.g., Obrebski et al., 2011). In addition, the 3-D model can be used to improve regional seismic event location based on short period surface waves, examples of which have been discussed by Barmin et al. (2011) and Levshin et al. (2012).

Acknowledgments. The facilities of the IRIS Data Management System, and specifically the IRIS Data Management Center, were used to access the waveform and metadata required in this study. The IRIS DMS is funded through the National Science Foundation and specifically the GEO Directorate through the Instrumentation and Facilities Program of the National Science Foundation under Cooperative Agreement EAR-0552316. This research was supported by NSF grants EAR-0711526, EAR-0844097, EAR-0750035, and EAR-1053291 at the University of Colorado at Boulder. 


\section{References}

Bailey, I.W., Miller, M.S., Liu, K.J. \& Levander, A., 2012. V-S and density structure beneath the Colorado Plateau constrained by gravity anomalies and joint inversions of receiver function and phase velocity data, Journal of Geophysical Research-Solid Earth, 117.

Barmin, M.P., A.L. Levshin, Y. Yang, and M.H. Ritzwoller (2011), Epicentral location based on Rayleigh wave empirical Green's functions from ambient seismic noise, Geophys. J. Int., 184 (2), 869-884.

Bensen, G. D., M. H. Ritzwoller, M. P. Barmin, a. L. Levshin, F. Lin, M. P. Moschetti, N. M. Shapiro, and Y. Yang (2007), Processing seismic ambient noise data to obtain reliable broad-band surface wave dispersion measurements, Geophysical Journal International, 169(3), 1239-1260, doi:10.1111/j.1365246X.2007.03374.x.

Bianchi, I., J. Park, N. Piana Agostinetti, and V. Levin (2010), Mapping seismic anisotropy using harmonic decomposition of receiver functions: An application to Northern Apennines, Italy, J. Geophys.

Res., 115, B12317, doi:10.1029/2009JB007061.

Bodin, T., M. Sambridge, H. Tkalčić, P. Arroucau, K. Gallagher, and N. Rawlinson (2012), Transdimensional inversion of receiver functions and surface wave dispersion, J. Geophys. Res., 117, B02301, doi:10.1029/2011JB008560.

Boyd, O.S., Jones, C.H. \& Sheehan, A.F., 2004. Foundering lithosphere imaged beneath the Southern Sierra Nevada, California, USA, Science, 305, 660-662.

Christensen, N.I. \& Mooney, W.D. (1995), Seismic velocity structure and composition of the continental crust: A global view, J. Geophys. Res., 100(B6): 9761-9788.

Chang, S.J., Baag, C.E. \& Langston, C.A. (2004), Joint analysis of teleseismic receiver functions and surface wave dispersion using the genetic algorithm, Bulletin of the Seismological Society of America, 94, 691-704.

Dziewonski, A. and D. Anderson (1981), Preliminary reference Earth model, Phys. Earth Planet. Int., 25(4): 297-356.

Frassetto, A. M., G. Zandt, H. Gilbert, T. J. Owens, and C. H. Jones (2011), Structure of the Sierra Nevada from receiver functions and implications for lithospheric foundering, Geosphere, 7, 898-921.

Gao, W., Grand, S.P., Baldridge, W.S., Wilson, D., West, M., Ni, J.F. \& Aster, R., 2004. Upper mantle convection beneath the central Rio Grande rift imaged by $\mathrm{P}$ and $\mathrm{S}$ wave tomography, Journal of Geophysical Research-Solid Earth, 109, 16.

Girardin, N. and V. Farra (1998), Azimuthal anisotropy in the upper mantle from observations of P-to-S converted phases: application to southeast Australia, Geophysical Journal International, 133, 615-629. 
Gilbert, H. (2012), Crustal structure and signatures of recent tectonism as influenced by ancient terranes in the western United States, Geosphere, 8, 141-157, doi:10.1130/GES00720.1.

Gorman, A.R., Clowes, R.M., Ellis, R.M., Henstock, T.J., Spence, G.D., Keller, G.R., Levander, A., Snelson, C.M., Burianyk, M.J.A., Kanasewich, E.R., Asudeh, I., Hajnal, Z. \& Miller, K.C., 2002. Deep probe: imaging the roots of western North America, Canadian Journal of Earth Sciences, 39, 375-398.

Hales, T.C., Abt, D.L., Humphreys, E.D. \& Roering, J.J., 2005. A lithospheric instability origin for Columbia River flood basalts and Wallowa Mountains uplift in northeast Oregon, Nature, 438, 842845.

Julia, J., Ammon, C.J., Herrmann, R.B. \& Correig, A.M. (2000), Joint inversion of receiver function and surface wave dispersion observations, Geophysical Journal International, 143, 99-112.

Kaban, M.K., Schwintzer, P., Artemieva, I.M. \& Mooney, W.D., 2003. Density of the continental roots: compositional and thermal contributions, Earth and Planetary Science Letters, 209, 53-69.

Kanamori, H. and D. Anderson (1977), Importance of physical dispersion in surface wave and free oscillation problems : Review, Revs. Geophys. Space Phys., 15(1):105-112.

Karato, S. (1993), Importance of anelasticity in the interpretation of seismic tomography, Geophys. Res. Lett., 20(15), 1623-1626, doi:10.1029/93GL01767.

Karlstrom, K.E., Whitmeyer, S.J., Dueker, K., Williams, M. L., Bowring, S., Levander, A., Humphreys, E. D., Keller, G. R., CR-Rom Working Group, 2005, Synthesis of results from the CD-ROM experiment: 4-D image of the lithosphere beneath the Rocky Mountains and implications for understanding the evolution of continental lithosphere, in: Karlstrom, K. E., and Keller, G. R., eds.,The Rocky Mountain region - an evolving lithosphere. AGU geophysical monograph, 154, DOI: 10:1029/154GM31.

Karlstrom, K.E., Coblentz, D., Dueker, K., Ouimet, W., Kirby, E., Van Wijk, J., Schmandt, B., Kelley, S., Lazear, G., Crossey, L.J., Crow, R., Aslan, A., Darling, A., Aster, R., MacCarthy, J., Hansen, S.M., Stachnik, J., Stockli, D.F., Garcia, R.V., Hoffman, M., McKeon, R., Feldman, J., Heizler, M., Donahue, M.S. \& Grp, C.W., 2012. Mantle-driven dynamic uplift of the Rocky Mountains and Colorado Plateau and its surface response: Toward a unified hypothesis, Lithosphere, 4, 3-22.

Langston, C. A. (1979), Structure under Mount Rainier, Washington, inferred from teleseismic body waves, J. Geophys. Res., 84(B9), 4749-4762, doi:10.1029/JB084iB09p04749.

Last, R. J., A. A. Nyblade, C. A. Langston, and T. J. Owens (1997), Crustal structure of the East African Plateau from receiver functions and Rayleigh wave phase velocities, J. Geophys. Res., 102(B11), 24,469-24,483, doi:10.1029/97JB02156.

Lawrence, J.F. \& Wiens, D.A., 2004. Combined receiver-function and surface wave phase-velocity inversion using a niching genetic algorithm: Application to Patagonia, Bulletin of the Seismological Society of America, 94, 977-987. 
Levander, A., Schmandt, B., Miller, M.S., Liu, K., Karlstrom, K.E., Crow, R.S., Lee, C.T.A. \& Humphreys, E.D., 2011. Continuing Colorado plateau uplift by delamination-style convective lithospheric downwelling, Nature, 472, 461-U540.

Ligorria, J. P., and C. J. Ammon (1999), Iterative deconvolution and receiver-function estimation, Bulletin of the Seismological Society of America, 89(5), 1395-1400.

Levshin, A.L., M.P. Barmin, M.P. Moschetti, C. Mendoza, and M.H. Ritzwoller (2012), Refinements to the method of epicentral location based on surface waves from ambient seismic noise: Introducing Love waves, Geophys. J. Int., submitted.

Lin, F-C., and M.H. Ritzwoller (2011a), Helmholtz surface wave tomography for isotropic and azimuthally anisotropic structure, Geophysical Journal International, 186, (3), 1104-1120, doi:10.1111/j.1365246X.2011.05070.x.

Lin, F.-C., \& Ritzwoller, M. H. (2011b), Apparent anisotropy in inhomogeneous isotropic media. Geophysical Journal International, 186(3), 1205-1219, doi:10.1111/j.1365-246X.2011.05100.x.

Lin, F.-C., Moschetti, M. P., \& Ritzwoller, M. H. (2008), Surface wave tomography of the western United States from ambient seismic noise: Rayleigh and Love wave phase velocity maps, Geophysical Journal International, 173(1), 281-298, doi:10.1111/j.1365-246X.2008.03720.x.

Lin, F-C., M.H. Ritzwoller, and R. Snieder, (2009), Eikonal tomography: surface wave tomography by phase front tracking across a regional broad-band seismic array, Geophysical Journal International, 177(3), 1091-1110, doi:10.1111/j.1365-246X.2009.04105.x.

Lin, F-C., M.H. Ritzwoller, Y. Yang, M.P. Moschetti, and M.J. Fouch (2010), Complex and variable crustal and uppermost mantle seismic anisotropy in the western United States, Nature Geoscience, 4(1), 55-61, doi:10.1038/ngeo1036.

Liu, Q.Y., Li, Y., Chen, J.H., van der Hilst, R.D., Guo, B.A., Wang, J., Qi, S.H. \& Li, S.C., (2010). Joint inversion of receiver function and ambient noise based on Bayesian theory, Chinese Journal of Geophysics-Chinese Edition, 53, 2603-2612.

Moschetti, M. P., Ritzwoller, M. H., \& Shapiro, N. M. (2007), Surface wave tomography of the western United States from ambient seismic noise: Rayleigh wave group velocity maps, Geochemistry Geophysics Geosystems, 8(8), 1-10, doi:10.1029/2007GC001655.

Moschetti, M. P., Ritzwoller, M. H., Lin, F., \& Yang, Y. (2010a), Seismic evidence for widespread western-US deep-crustal deformation caused by extension, Nature, 464(7290), 885-9, doi:10.1038/nature08951. 
Moschetti, M. P., Ritzwoller, M. H., Lin, F.-C., \& Yang, Y. (2010b), Crustal shear wave velocity structure of the western United States inferred from ambient seismic noise and earthquake data, Journal of Geophysical Research, 115, B10, 1-20, doi:10.1029/2010JB007448.

Obrebski, M., Allen, R.M., Pollitz, F. \& Hung, S.H., 2011. Lithosphere-asthenosphere interaction beneath the western United States from the joint inversion of body-wave traveltimes and surface-wave phase velocities, Geophysical Journal International, 185, 1003-1021.

Ozalaybey, S., Savage, M.K., Sheehan, A.F., Louie, J.N. \& Brune, J.N., 1997. Shear-wave velocity structure in the northern Basin and Range province from the combined analysis of receiver functions and surface waves, Bulletin of the Seismological Society of America, 87, 183-199.

Pollitz, F.F. (2008), Observations and interpretation of fundamental mode Rayleigh wavefields recorded by the Transportable Array (USArray), Geophys. J. Int., 173, 189-204.

Pollitz, F. F. \& Snoke, J. A. (2010), Rayleigh-wave phase-velocity maps and three-dimensional shear velocity structure of the western US from local non-plane surface wave tomography, Geophys. J. Int., $180,1153-1169$.

Ritzwoller, M. H., Lin, F.-C., \& Shen, W. (2011). Ambient noise tomography with a large seismic array. Comptes Rendus Geoscience, 343(8-9), 558-570, doi:10.1016/j.crte.2011.03.007.

Schmandt, B. \& Humphreys, E., 2010. Complex subduction and small-scale convection revealed by bodywave tomography of the western United States upper mantle, Earth and Planetary Science Letters, 297, 435-445.

Shapiro, N. M., \& Ritzwoller, M. H. (2002), Monte-Carlo inversion for a global shear-velocity model of the crust and upper mantle, Geophysical Journal International, 151, 88-105.

Shapiro, N. M., Campillo, M., Stehly, L., \& Ritzwoller, M. H. (2005), High-resolution surface-wave tomography from ambient seismic noise, Science (New York, N.Y.), 307(5715), 1615-8, doi:10.1126/science.1108339.

Shen, W., M.H. Ritzwoller, V. Schulte-Pelkum, F.-C. Lin (2012), Joint inversion of surface wave dispersion and receiver functions: A Bayesian Monte-Carlo approach, Geophys. J. Int., submitted. (preprint at http://ciei.colorado.edu/pubs/2012/Joint_Inversion_Submitted_GJI.pdf)

Tokam, A.P.K., Tabod, C.T., Nyblade, A.A., Julia, J., Wiens, D.A. \& Pasyanos, M.E., 2010. Structure of the crust beneath Cameroon, West Africa, from the joint inversion of Rayleigh wave group velocities and receiver functions, Geophysical Journal International, 183, 1061-1076.

West, M., Ni, J., Baldridge, W.S., Wilson, D., Aster, R., Gao, W. \& Grand, S., 2004. Crust and upper mantle shear wave structure of the southwest United States: Implications for rifting and support for high elevation, Journal of Geophysical Research-Solid Earth, 109, 16. 
Whitmeyer S. J., Karlstrom K. E., 2007, Tectonic model for the Proterozoic growth of North America, Geosphere, 3, 220-259.

Yang, Y. \& Forsyth, D. (2006). Regional tomographic inversion of the amplitude and phase of Rayleigh waves with 2-D sensitivity kernels, Geophys. J. Int., 166, 1148-1160.

Yang, Y., M. H. Ritzwoller, F.-C. Lin, M. P. Moschetti, and N. M. Shapiro (2008), Structure of the crust and uppermost mantle beneath the western United States revealed by ambient noise and earthquake tomography, Journal of Geophysical Research, 113, B12, 1-9, doi:10.1029/2008JB005833.

Zandt, G., Gilbert, H., Owens, T.J., Ducea, M., Saleeby, J. \& Jones, C.H., 2004. Active foundering of a continental arc root beneath the southern Sierra Nevada in California, Nature, 431, 41-46. 


\section{Figure Captions}

Figure 1. Example Rayleigh wave phase speed maps determined from $(a, b)$ ambient noise data using eikonal tomography (ANT) and (c,e,f) earthquake data using Helmholtz tomography (ET) at the periods indicated. (d) Histogram of the differences in phase speeds at $30 \mathrm{sec}$ period using ambient noise and earthquake data: mean difference is -1 $\mathrm{m} / \mathrm{s}$ and the standard deviation of the difference is $20 \mathrm{~m} / \mathrm{s}$. Geological provinces are delineated by black lines in the maps.

Figure 2. Example outcome of the joint inversion at USArray TA station R11A in the Basin and Range province in Currant, Nevada (38.35, -115.59). (a) Observed Rayleigh wave phase speed curve presented as $1 \sigma$ error bars. Predictions from the ensemble of accepted models in (d) are shown (grey lines), as is the prediction from the best fitting model (refdline). (b) The azimuthally independent receiver function $\mathrm{R}_{0}(\mathrm{t})$ is shown with the black lines defining the estimated $1 \sigma$ uncertainty. Predictions from the members of the ensemble in (b) are shown with grey lines, and the red line is the best fitting member of the ensemble. (c) Ensemble of accepted model using surface wave data alone. The full width of the ensemble is presented as black lines enclosing a grey-shaded region, the $1 \sigma$ ensemble is shown with red lines, and the average model is the black curve near the middle of the ensemble. Moho is identified as a dashed line at $\sim 32 \mathrm{~km}$. (b) Ensemble of accepted models from the joint inversion.

Figure 3. (a)-(c) Prior and posterior (surface waves only) marginal distributions of three model variables are presented with white and red histograms, respectively, for crustal thickness, the Vsv contrast across Moho, and Vsv at $120 \mathrm{~km}$ depth. (d)-(f) Same as (a)-(c), but the red histogram is for the posterior marginal distribution resulting from the joint inversion of receiver functions and surface wave phase velocities.

Figure 4. Six examples of azimuthally independent receiver functions (pair of black lines) and Rayleigh wave phase speed curves (error bars) compared with predictions from the best-fitting model from the joint inversion (red lines) found in Fig. 5. (a) TA station D10A, Oakesdale, WA (47.05, -117.28). (b) Station F22A, Rosebud, MT (45.78, 106.26). (c) Station N23A, Red Feather Lakes, CO (40.89, -105.94). (d) Station T19A, 
Beclabito, NM (36.83, -109.02). (e) Station X14A, Yava, AR (34.47, -112.89). (f) Station O15A, Rush Valley, UT (40.28, -112.47).

Figure 5. The ensembles of accepted models (defined as in Fig. 2c,d) from the joint inversion determined from the corresponding pairs of receiver functions and Rayleigh wave phase speed curves found in Fig. 4.

Figure 6. (a) Average of Vsv from the distribution of accepted models from the joint inversion in the depth range from 105 to $135 \mathrm{~km}$, presented as a mosaic of results at each station location. (b) The same as (a), but wave speeds have been interpolated onto a $0.5^{\circ} \times 0.5^{\circ}$ grid by simple-kriging, in which model uncertainties guide the interpolation.

Figure 7. Average of Vsv from the distribution of accepted models from the joint inversion at three depths. (a) Average of the model between 0 and $8 \mathrm{~km}$ depth, (b) average of the model in the lower $4 \mathrm{~km}$ of the crust above Moho, and (c) the average of the model in the depth range between 50 and $70 \mathrm{~km}$.

Figure 8. Estimates of uncertainties $(1 \sigma)$ in the 3-D model at three four depths: (a) 0-8 $\mathrm{km}$ average, (b) lower crustal average (4 km above Moho to Moho), (c) $60 \mathrm{~km}$, and (d) $120 \mathrm{~km}$.

Figure 9. Average of (a) crustal thickness and (b) the jump in Vsv across the Moho from the ensemble of accepted models derived from the joint inversion. Vertical model profiles that are plotted in Fig. 11 are identified in (b).

Figure 10. Estimates of uncertainty $(1 \sigma)$ for (a) estimated crustal thickness and (b) the jump in shear wave speed across the Moho. (c) Model uncertainties ( $1 \sigma$ ) averaged over the study region from the inversion with surface wave (SW) data alone (black line) and from the joint inversion (red line).

Figure 11. Vertical Vsv model profiles for the six transects identified in Fig. 9b with dashed lines. Speeds in the crust are in absolute units and those in the mantle are presented as percent perturbations relative $4.4 \mathrm{~km} / \mathrm{s}$, except along profile C-C' where it is $4.32 \mathrm{~km} / \mathrm{s}$. Mantle velocity contours appear at 3\% intervals. (RGR: Rio Grande Rift, CR: 
Cascade Range, SRP: Snake River Plain, BH: Bighorn Range, CV: Central Valley; SN: Sierra Nevada; CB: Cheyenne Belt). 
(a) $\quad$ ANT, period $=8 \mathrm{sec}$

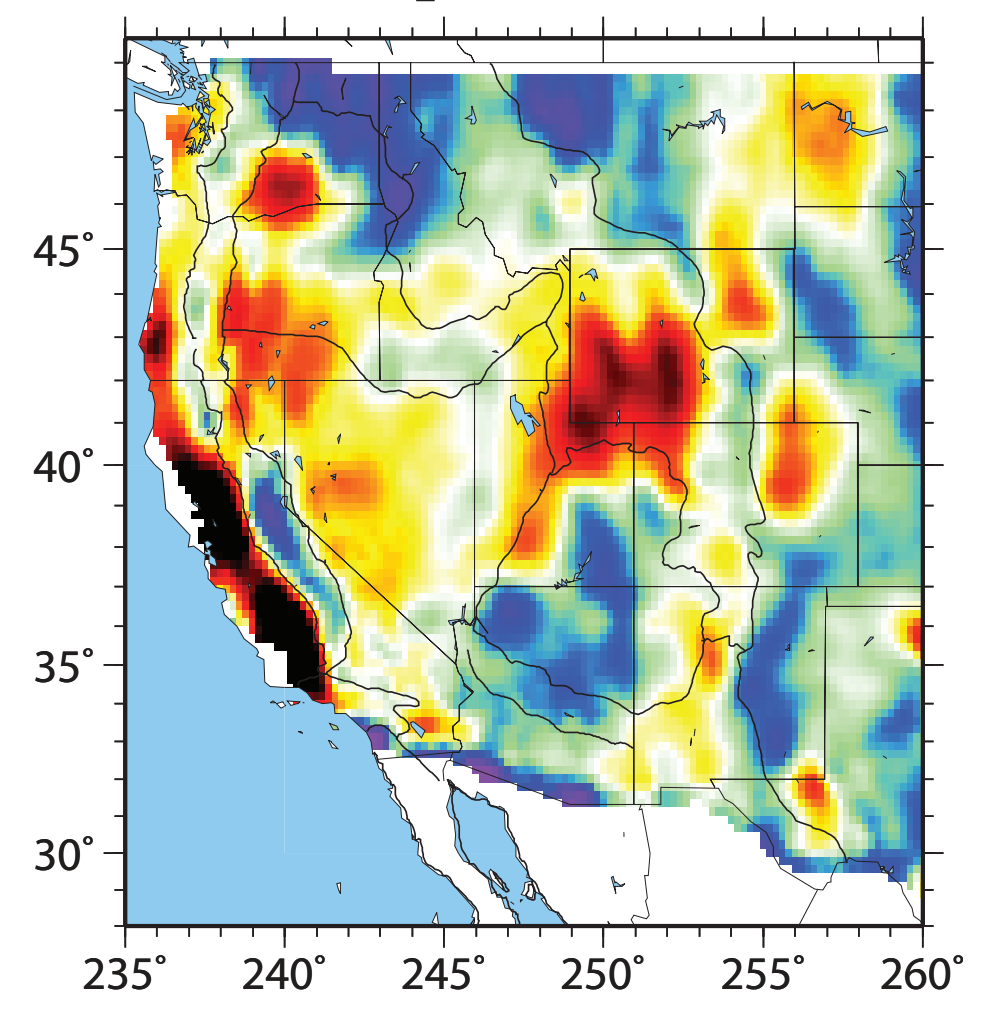

$\begin{array}{lllllllll}2.80 & 2.92 & 2.98 & 3.04 & 3.10 & 3.16 & 3.22 & 3.28 & 3.40\end{array}$ Phase Velocity $(\mathrm{km} / \mathrm{sec})$

(d)

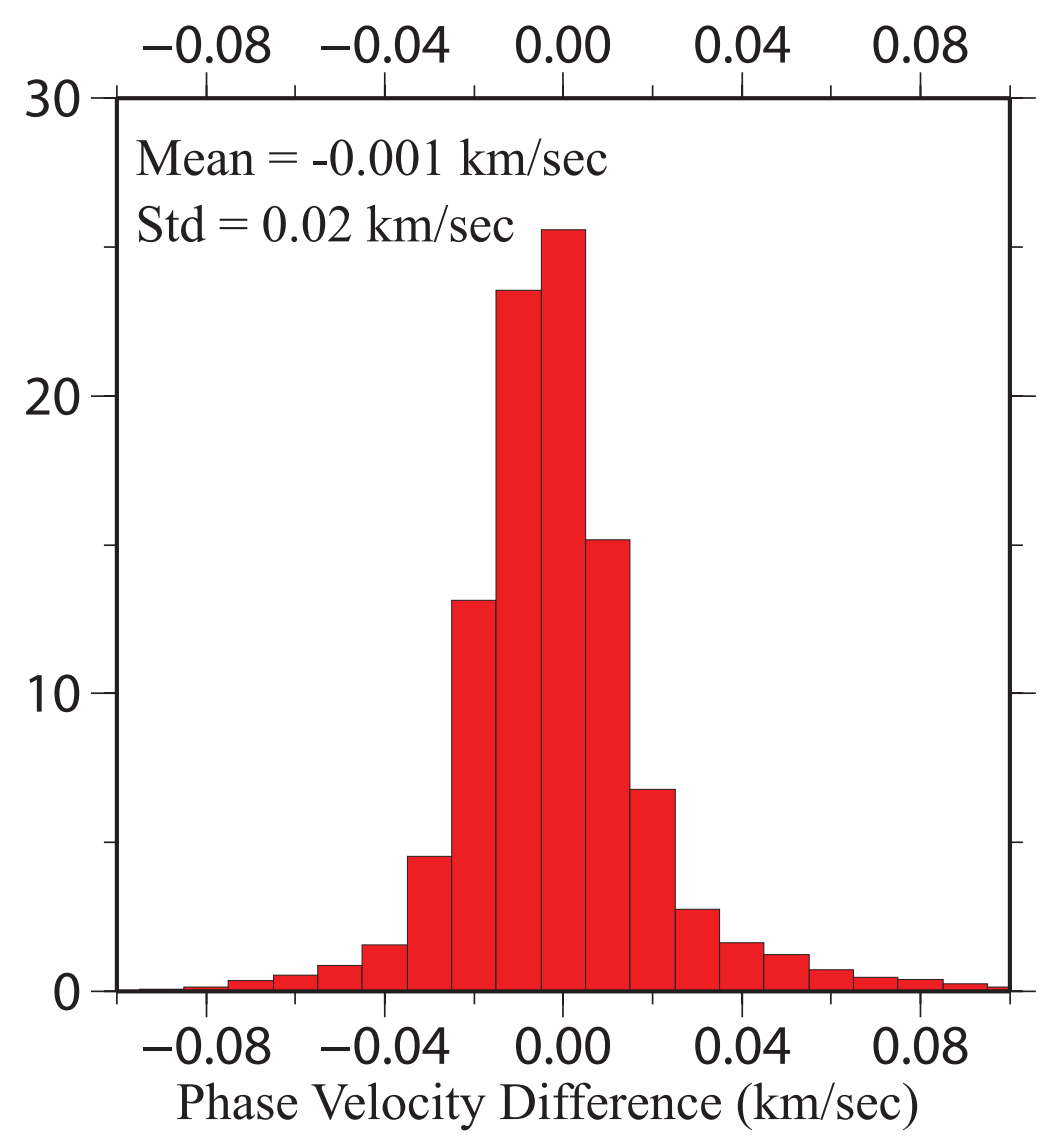

(b) ANT, period $=30 \mathrm{sec}$

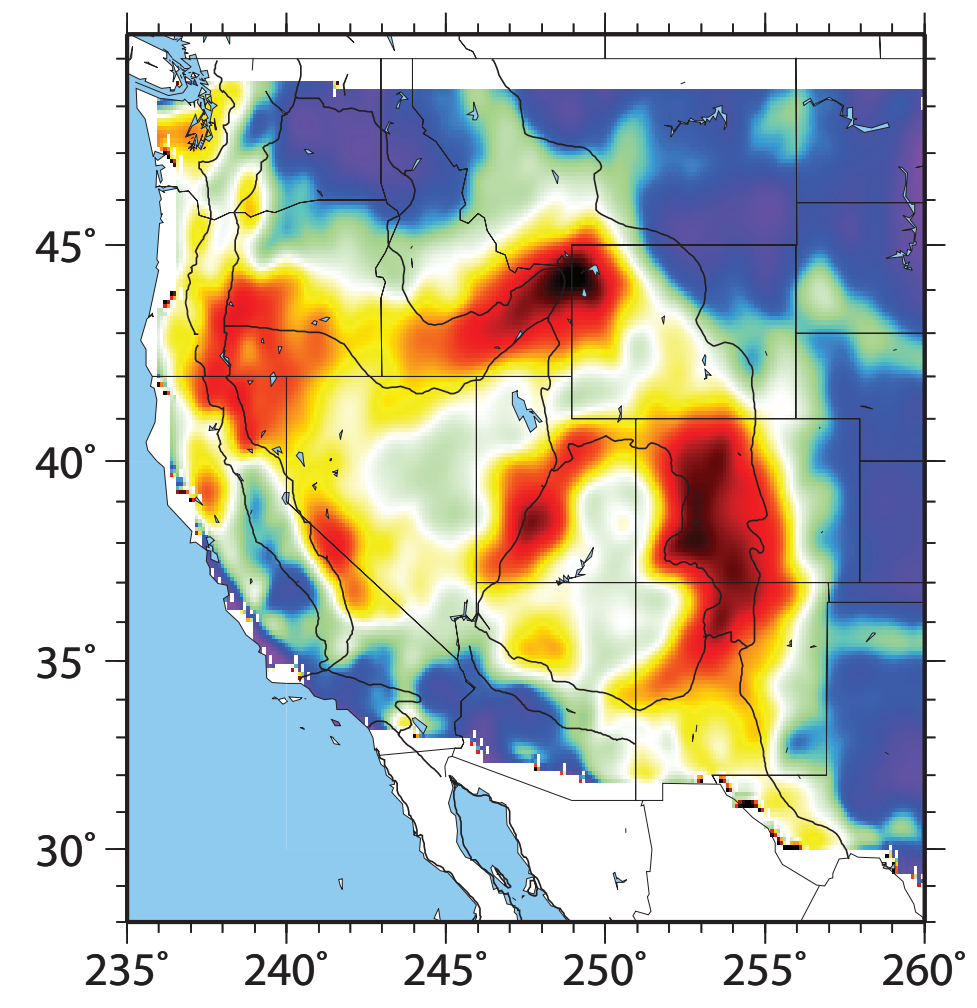

$\begin{array}{lllllllll}3.45 & 3.54 & 3.58 & 3.63 & 3.67 & 3.72 & 3.76 & 3.81 & 3.90\end{array}$ Phase Velocity $(\mathrm{km} / \mathrm{sec})$

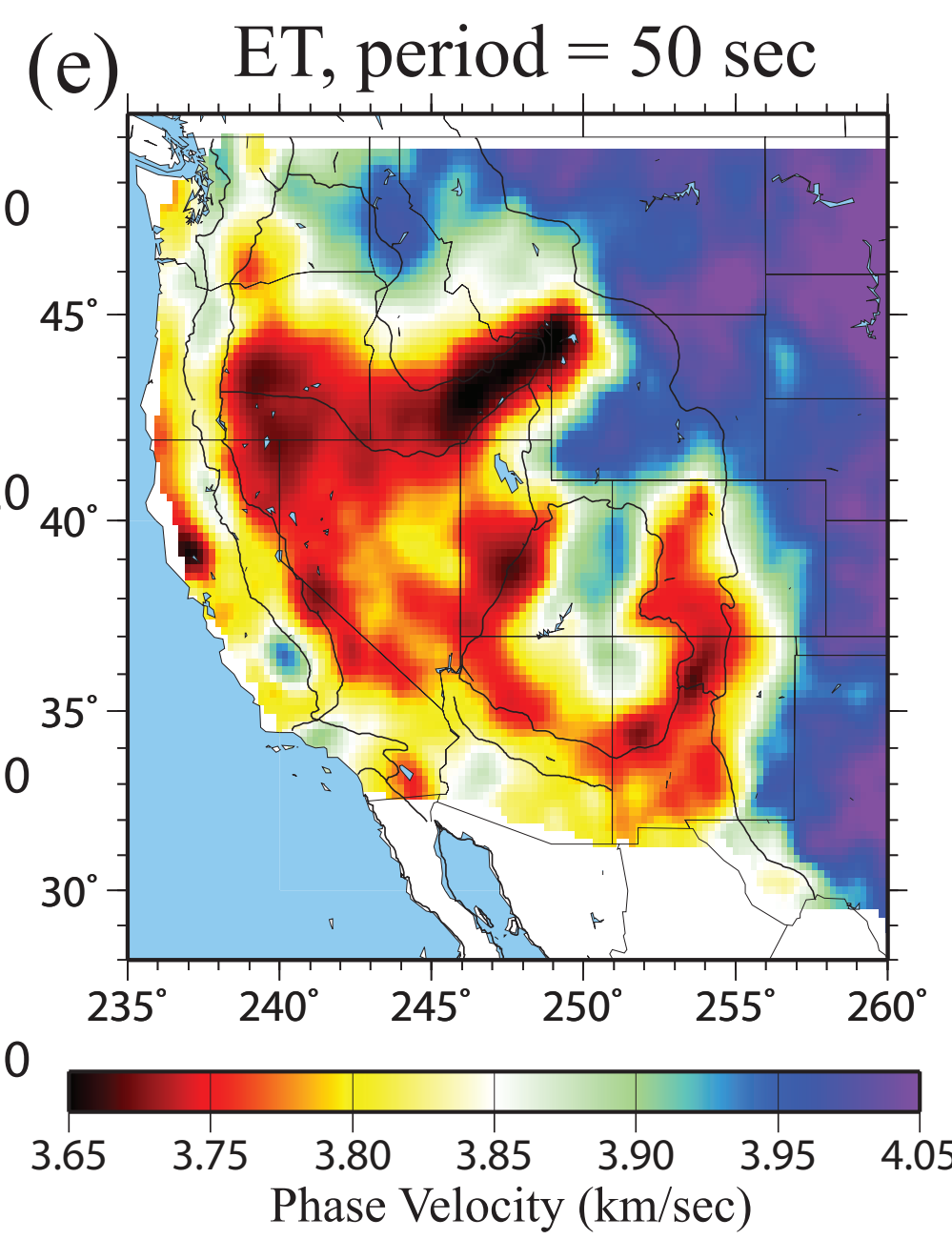

(c) $\mathrm{ET}$, period $=30 \mathrm{sec}$

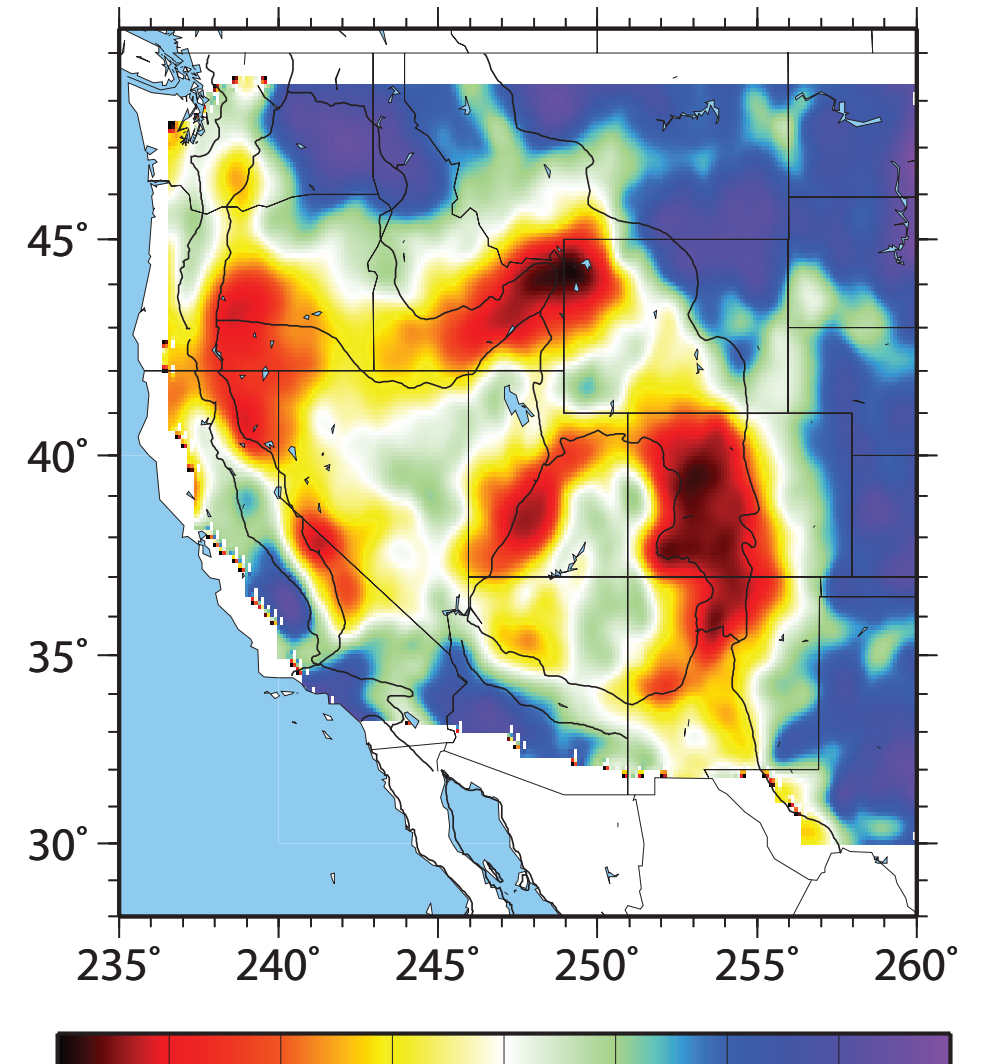

$\begin{array}{lllllllll}3.45 & 3.54 & 3.58 & 3.63 & 3.67 & 3.72 & 3.76 & 3.81 & 3.90\end{array}$ Phase Velocity $(\mathrm{km} / \mathrm{sec})$

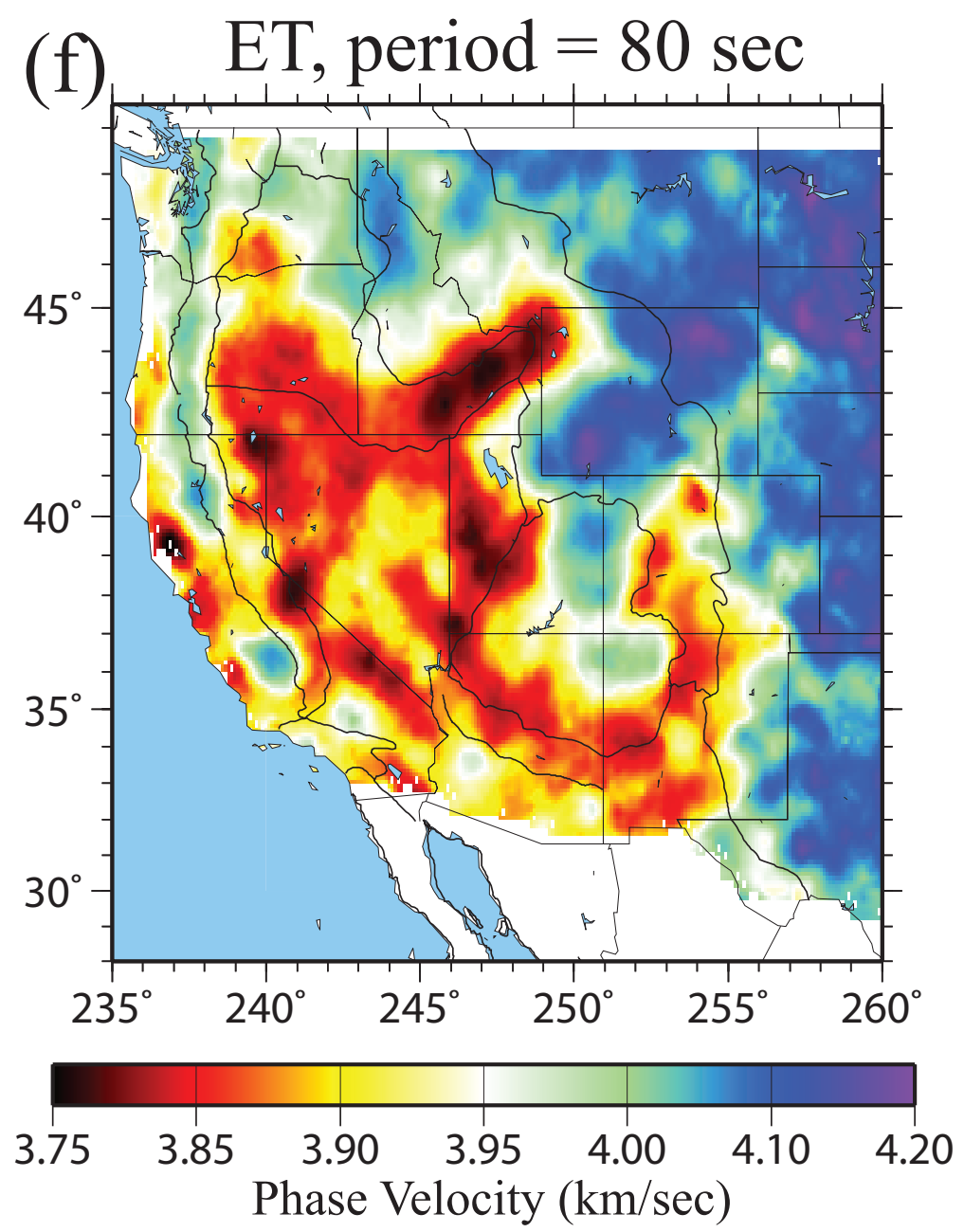


R11A in Basin and Range Surface wave
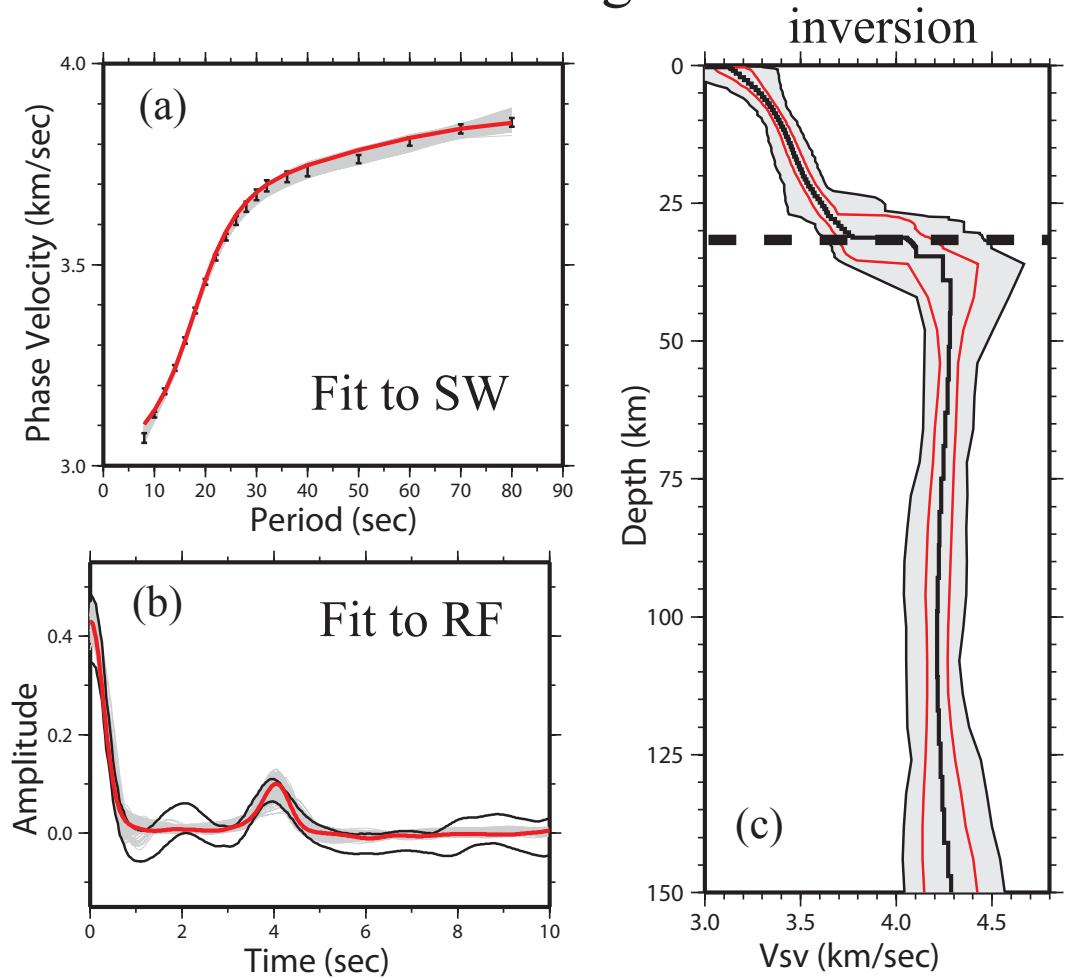

Joint inversion

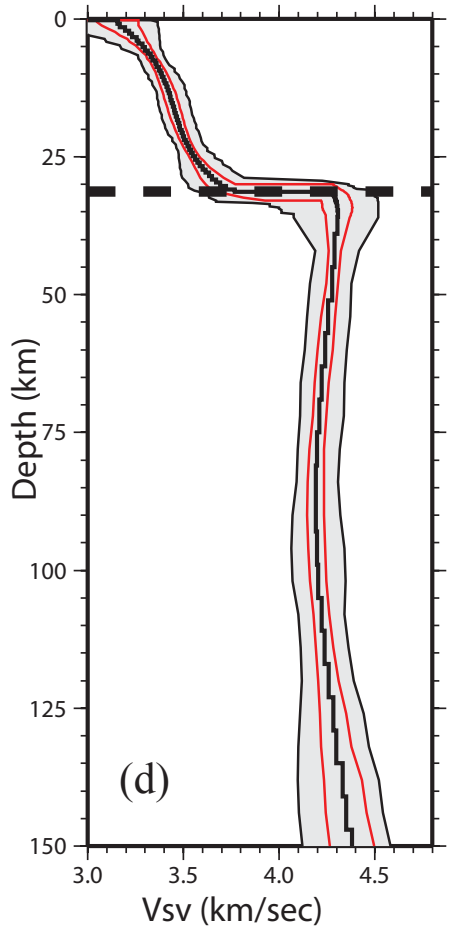




\section{Surface wave}

inversion

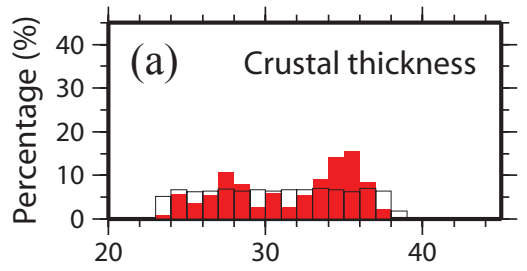

(km)
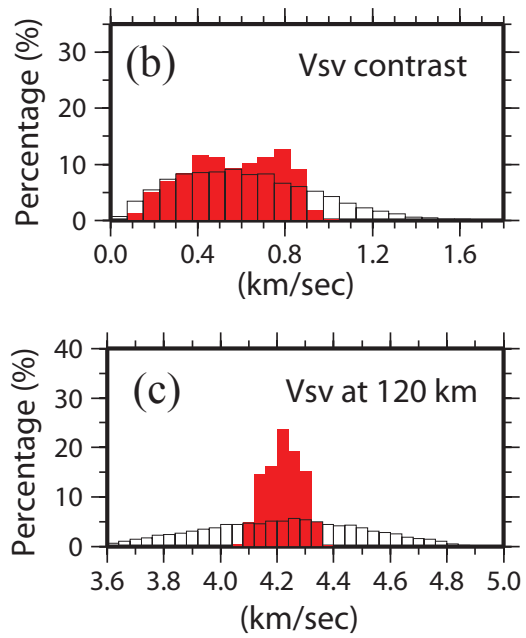

\section{Joint inversion}
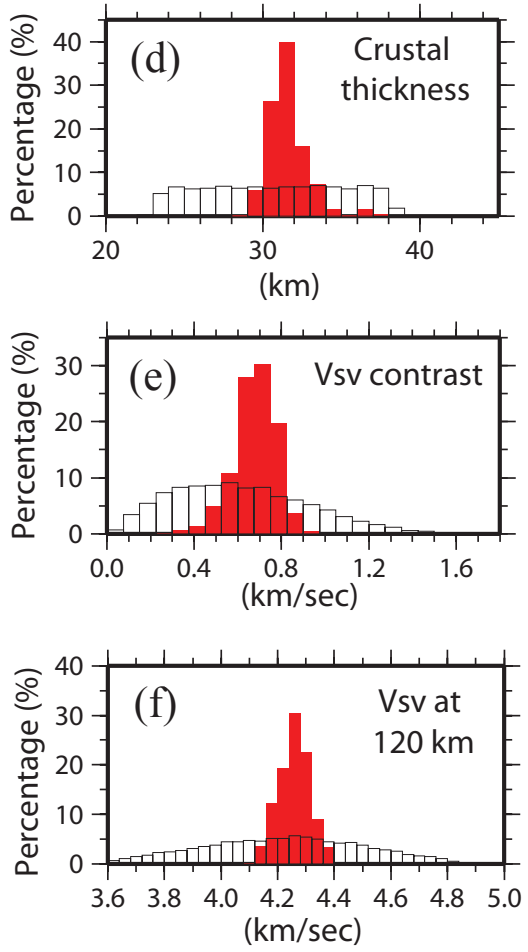
(a) D10A in Washington
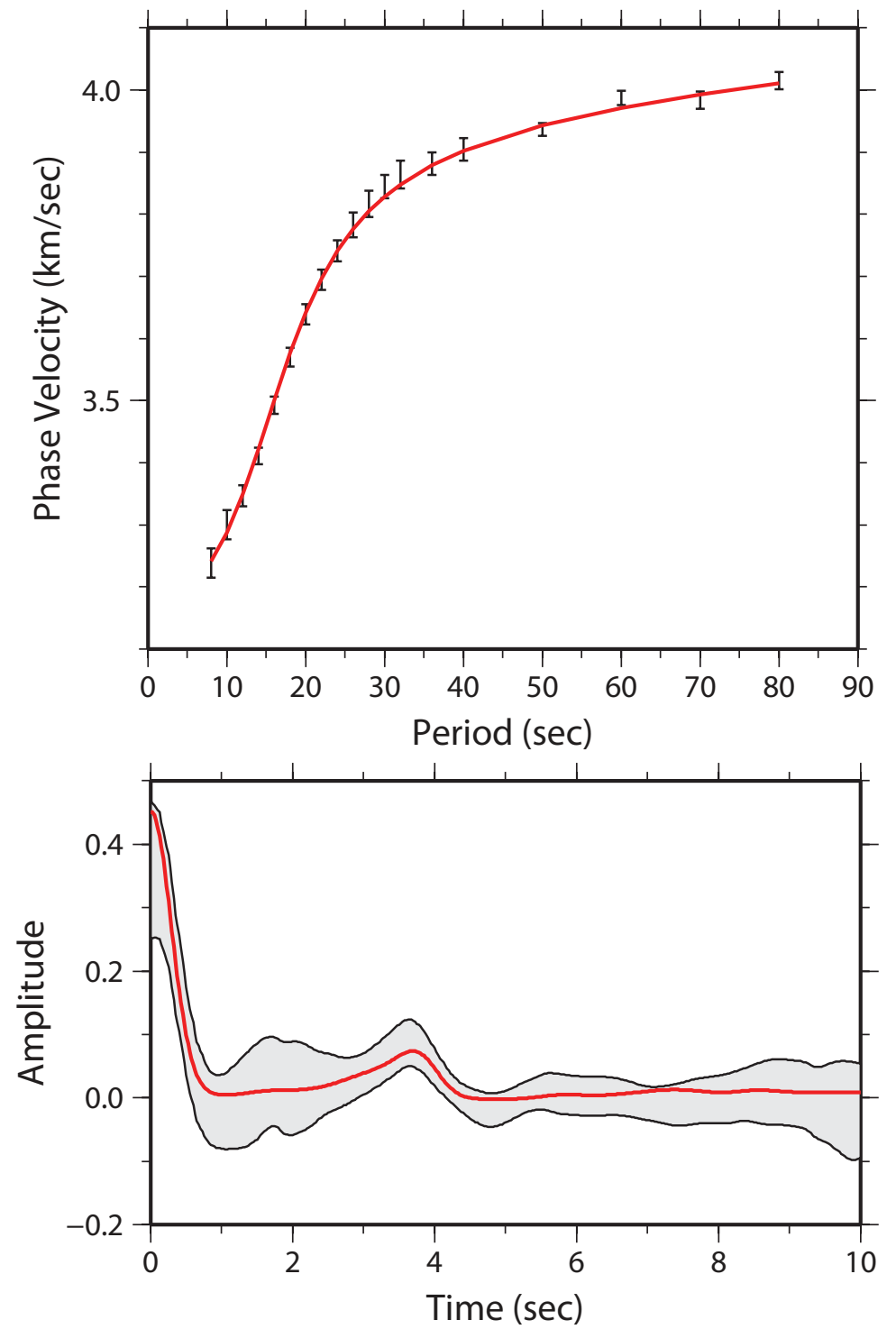

(d) T19A in New Mexico
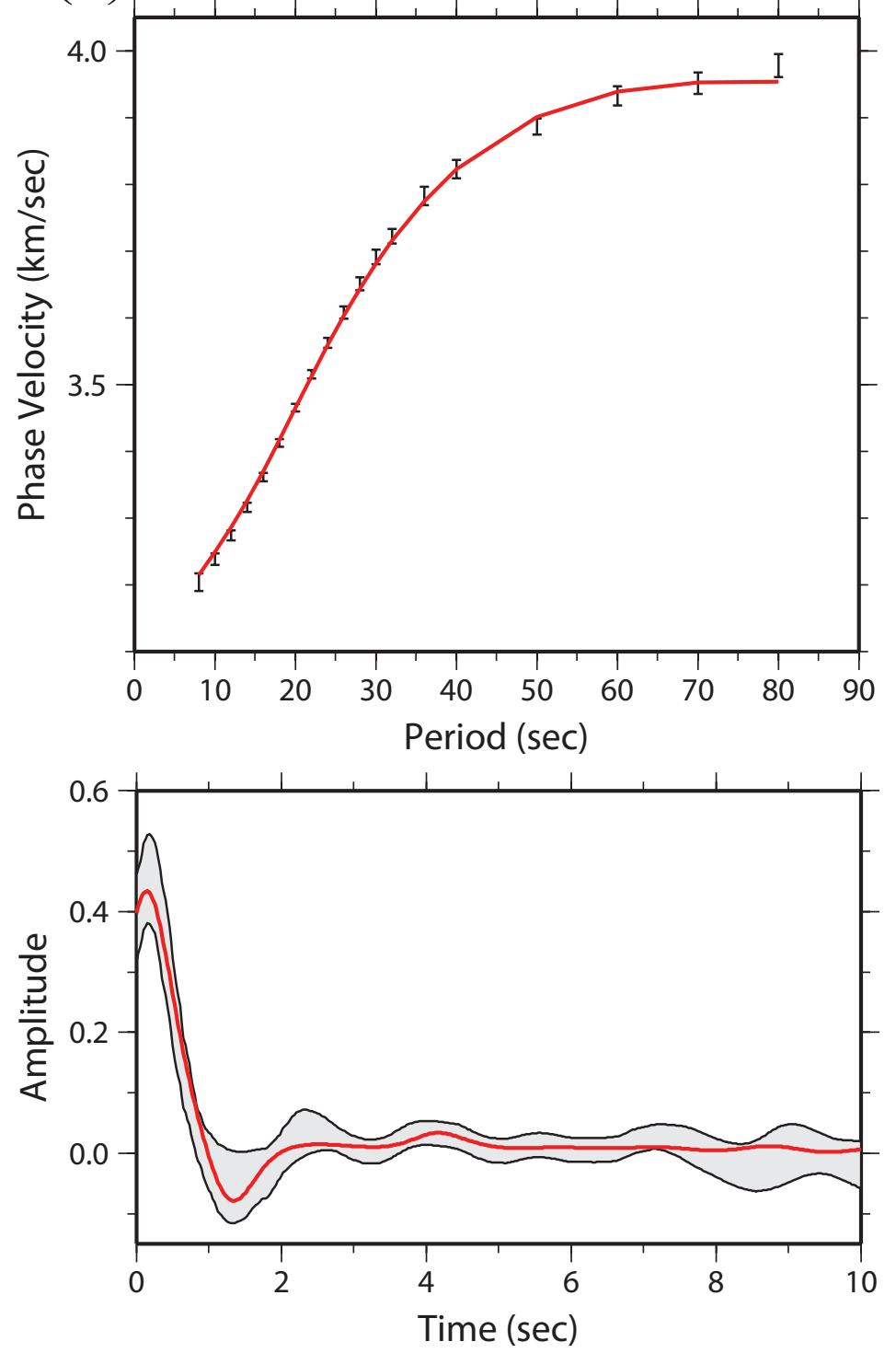

(b) F22A in Montana
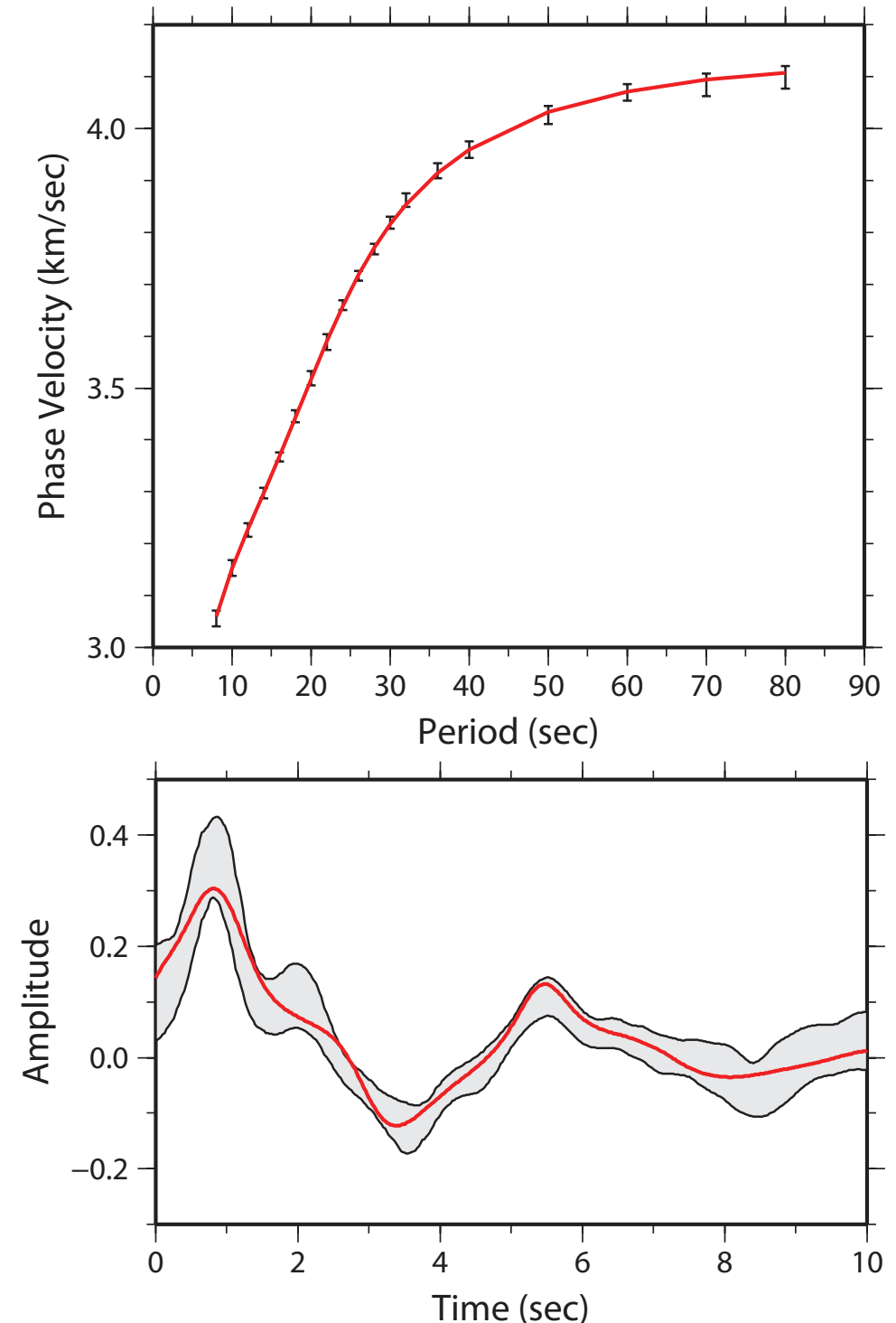

(e) X14A in Arizona
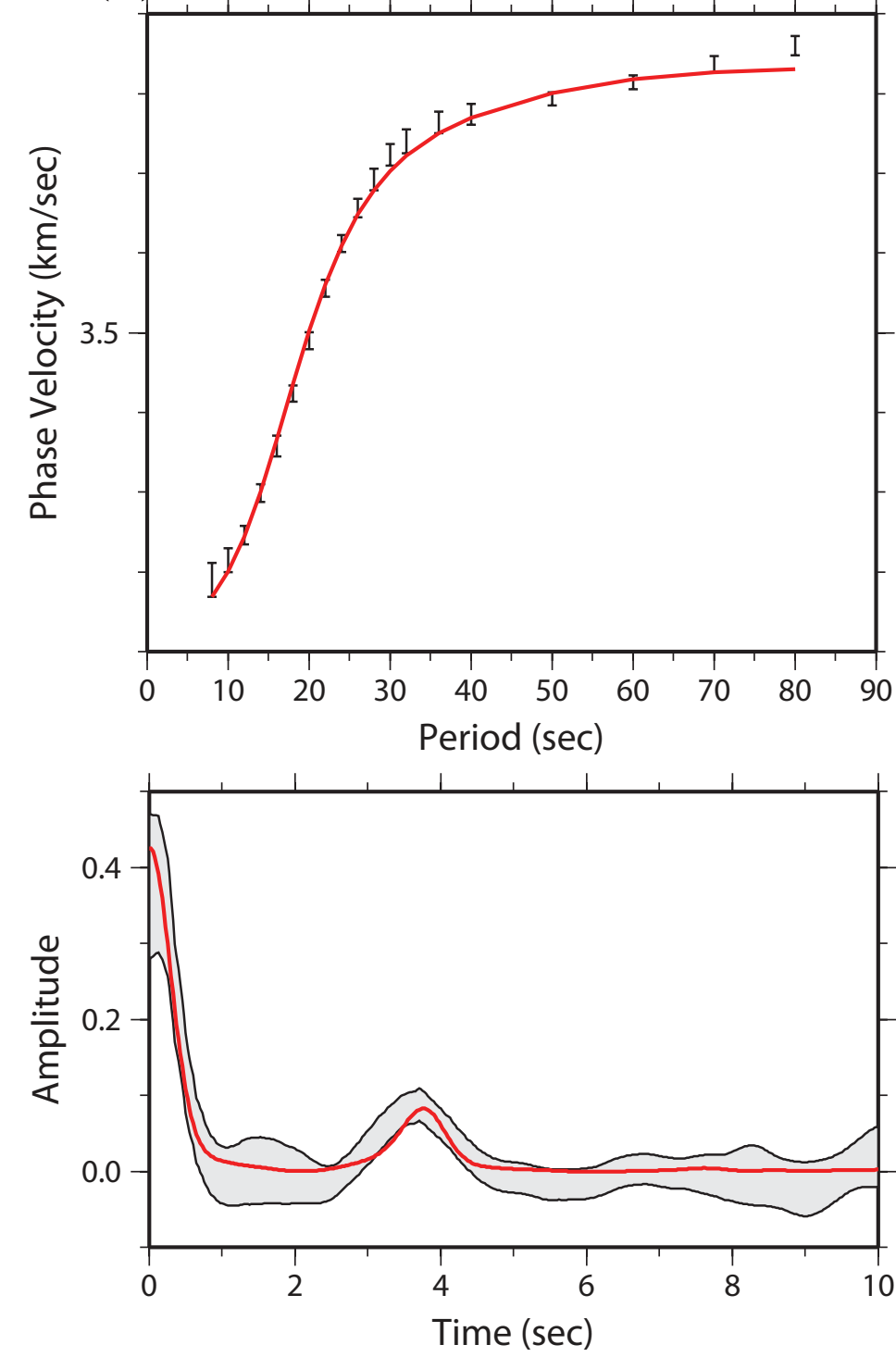

(c) N23A in Colorado
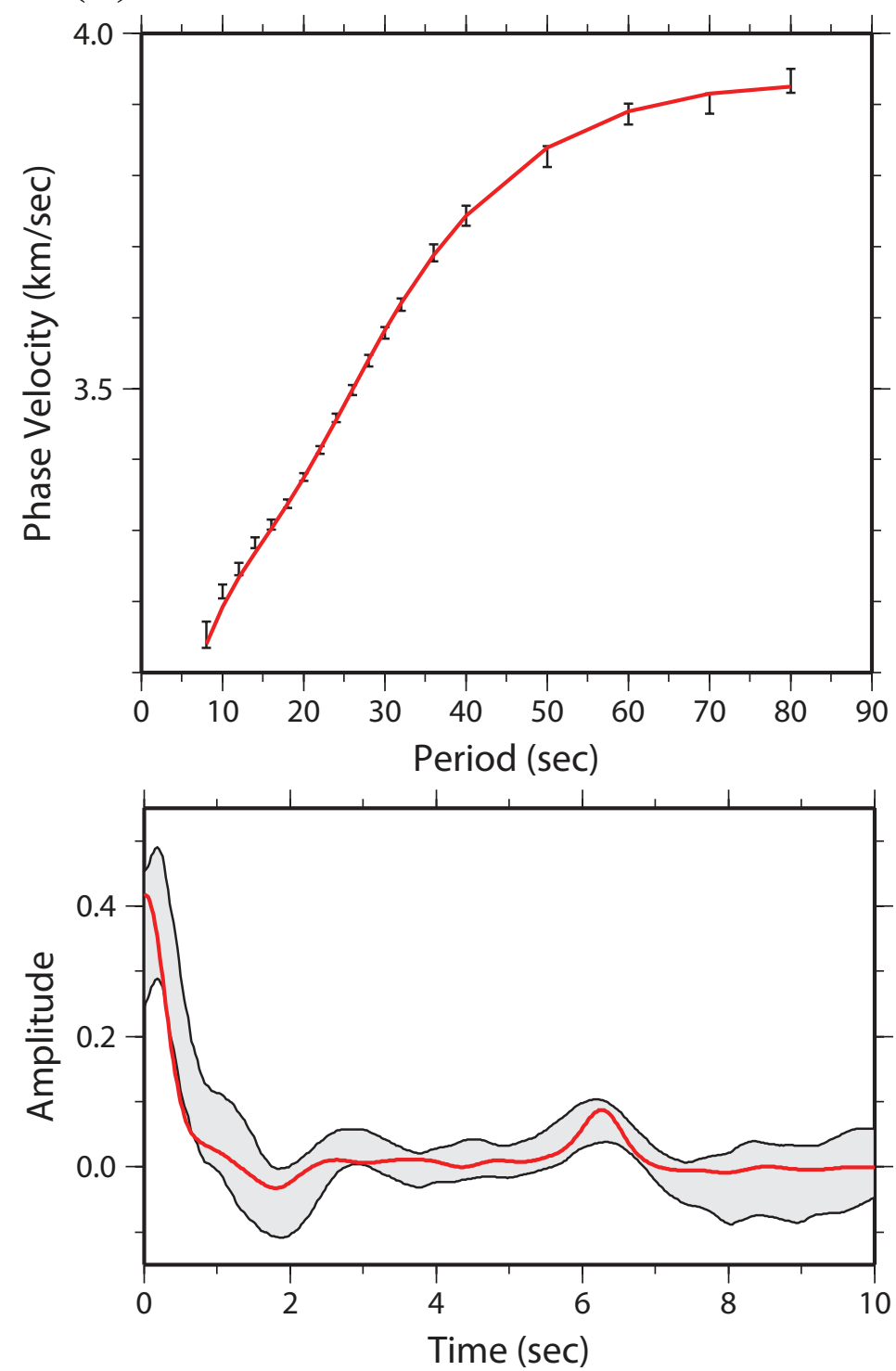

(f) O15A in Utah
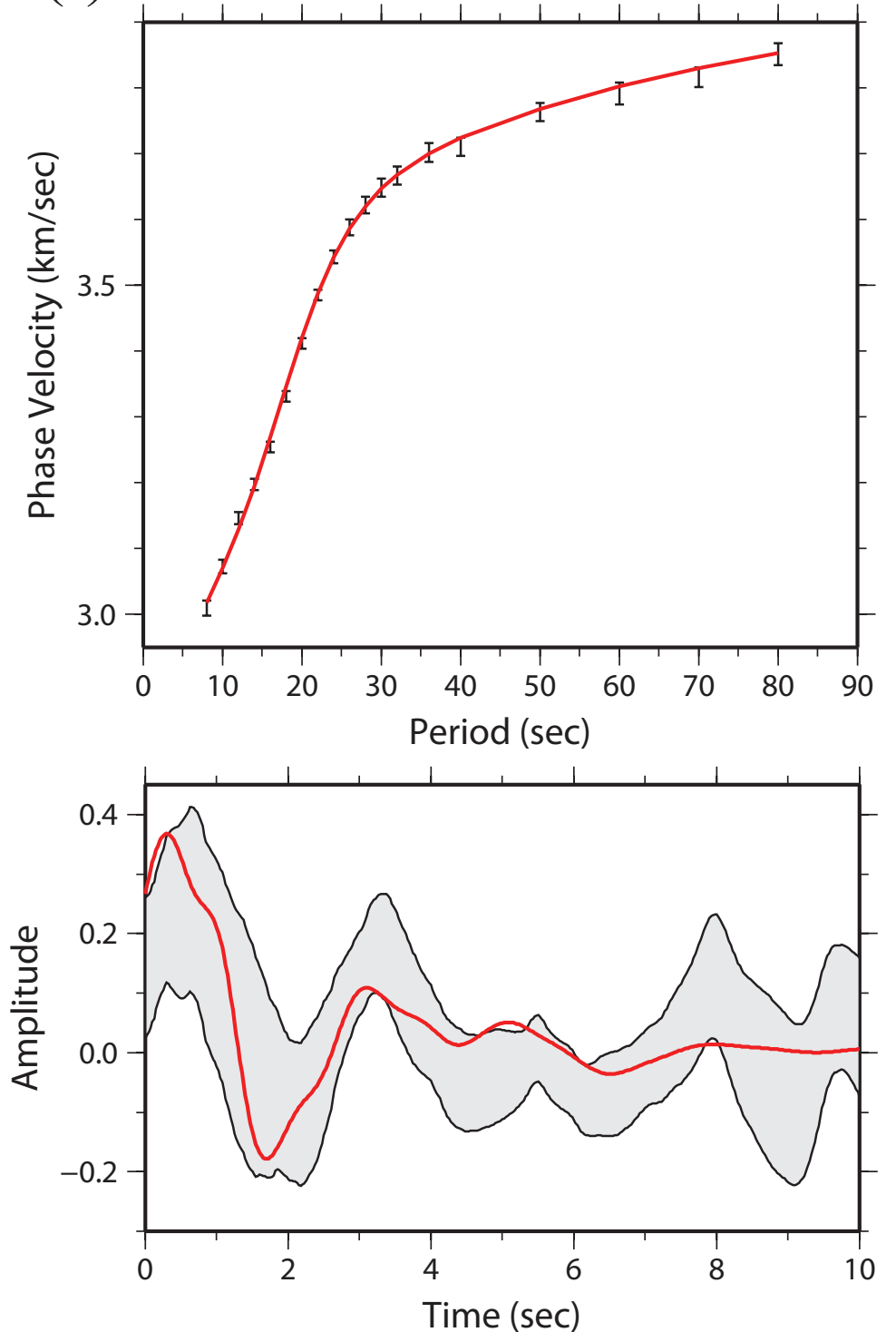
Figure 5

(a)

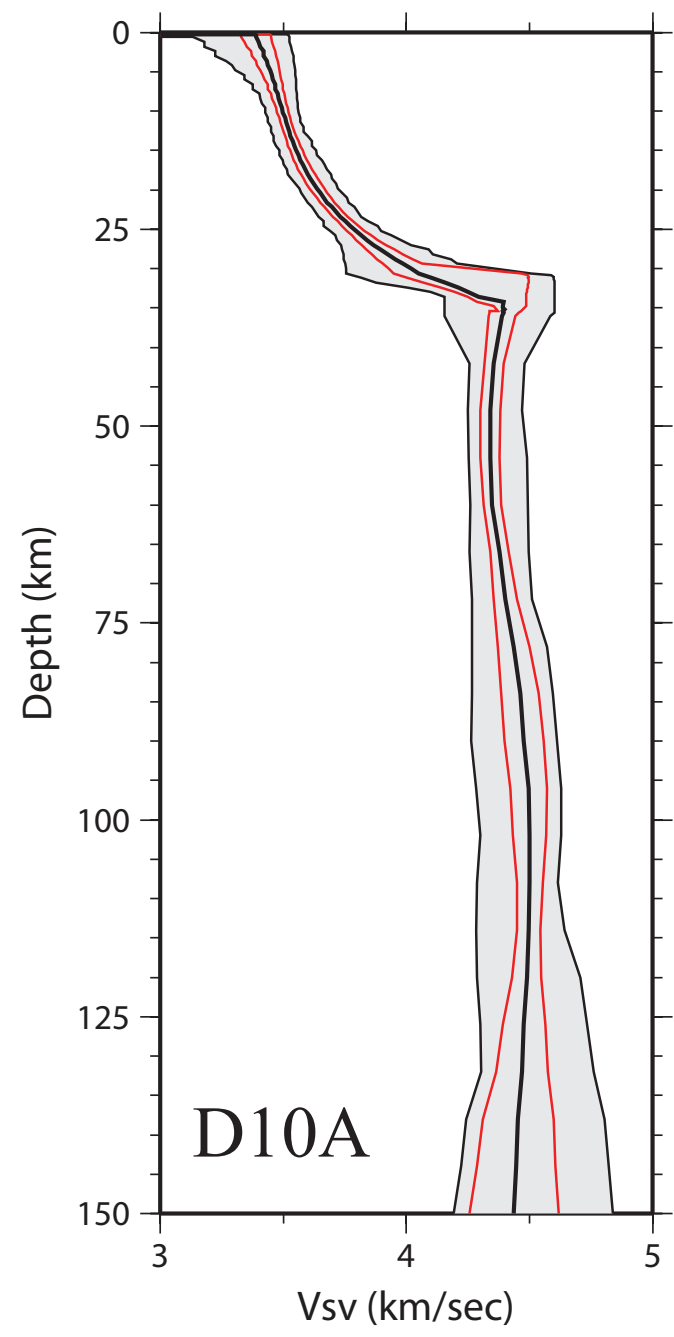

(d)

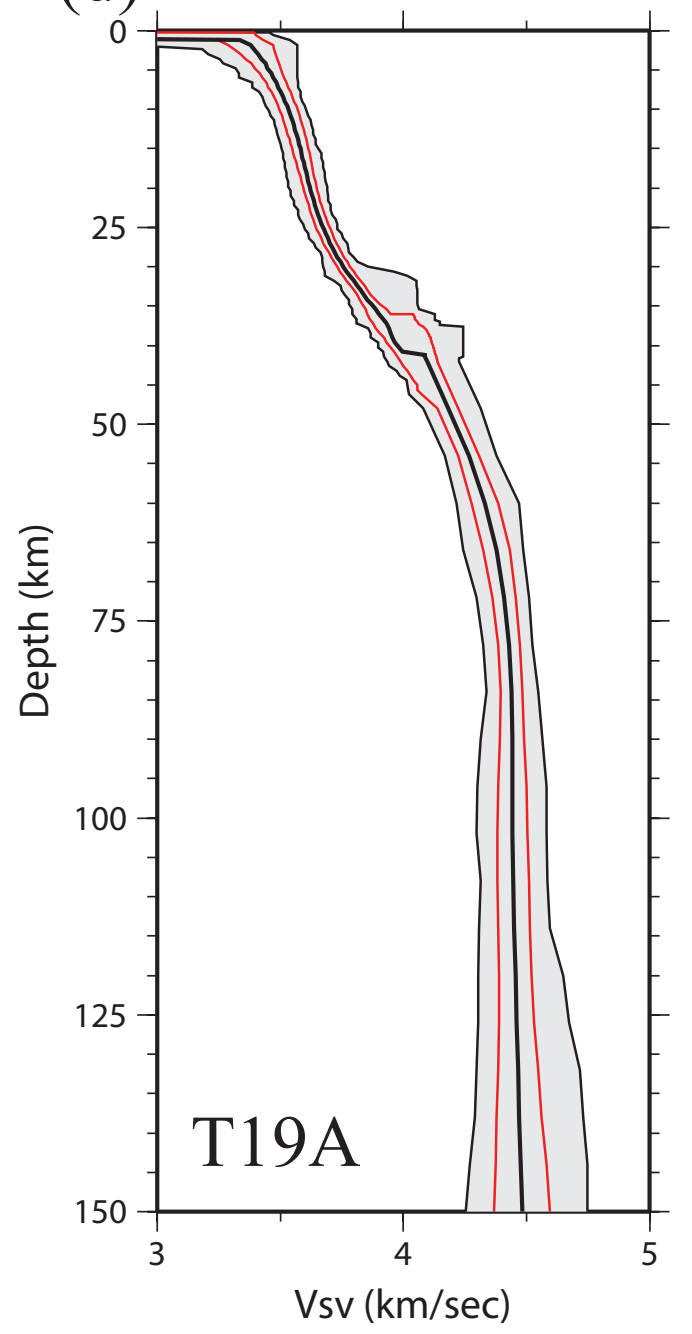

(b)

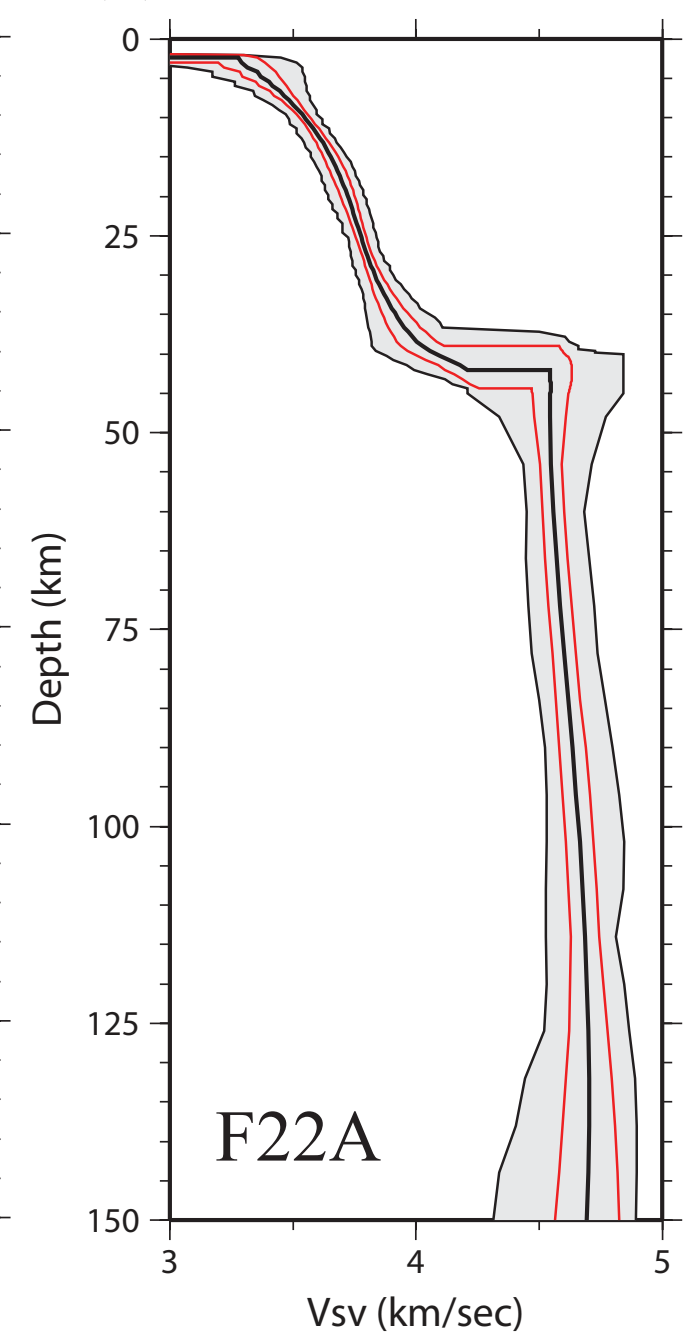

(e)

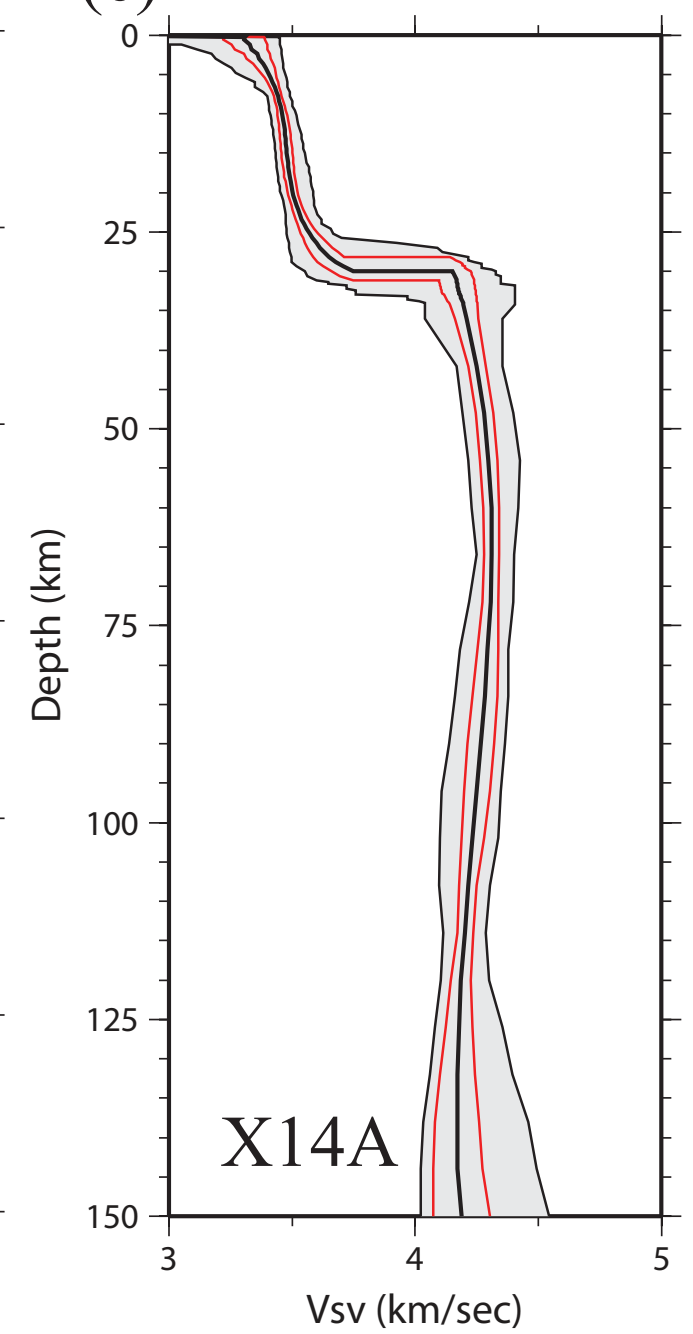

(c)

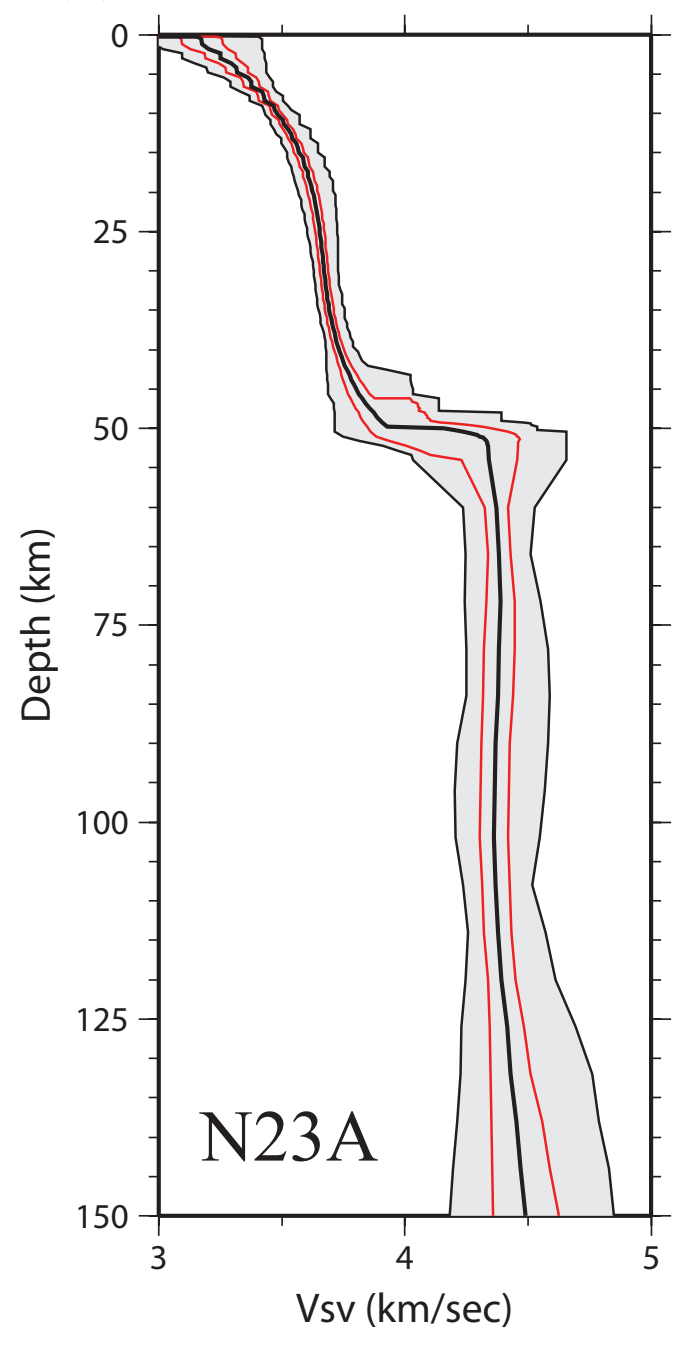

(f)

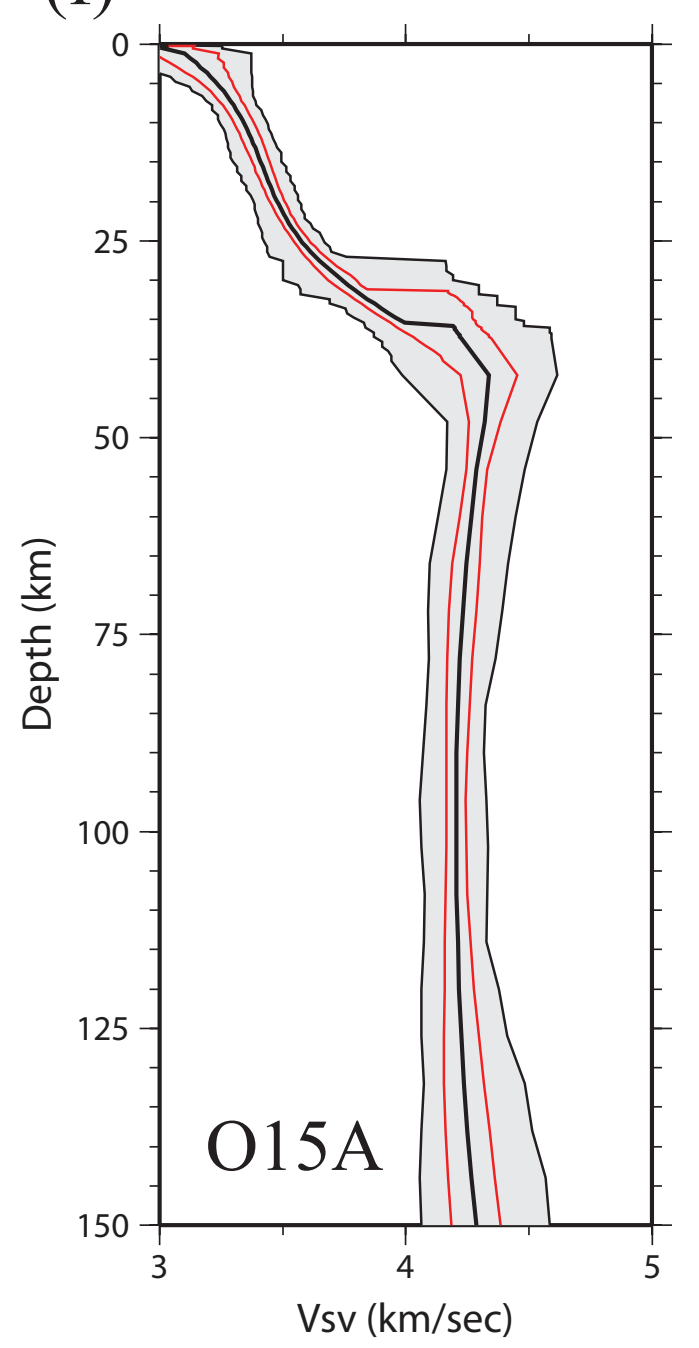


Fig 6

(a) $120 \mathrm{~km}$

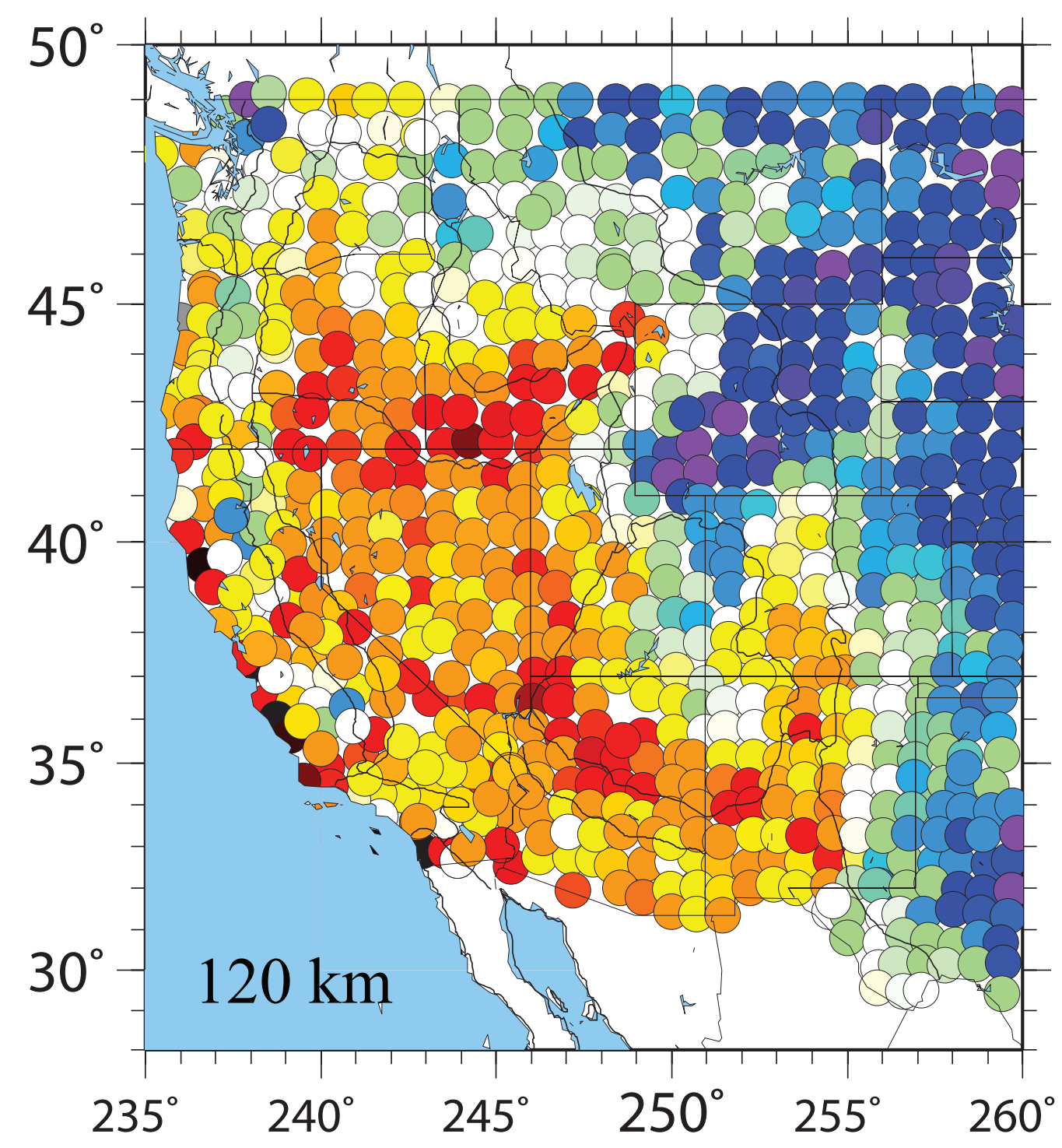

(b) $120 \mathrm{~km}$

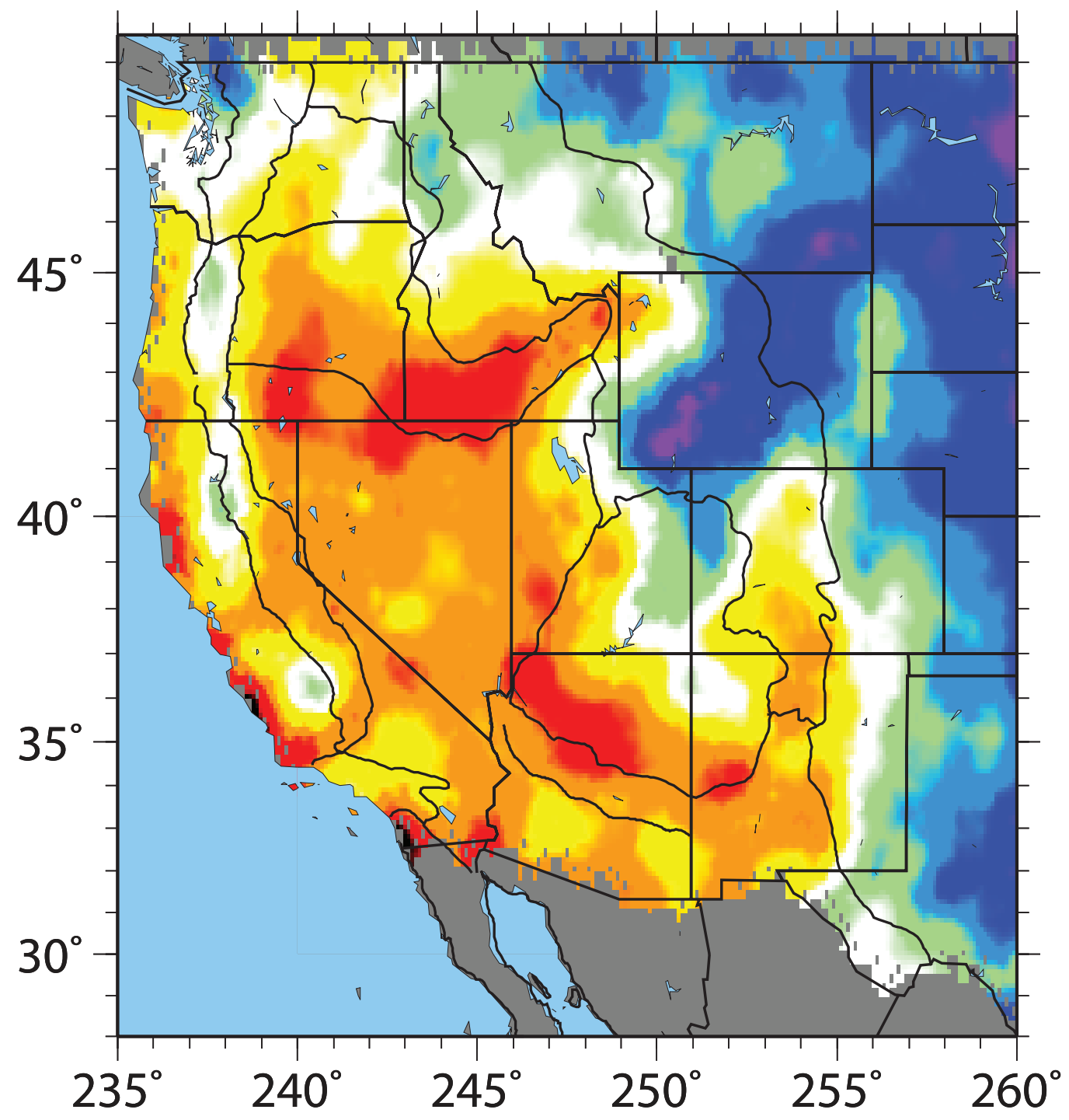

\section{$\begin{array}{lllllll}4.1 & 4.2 & 4.3 & 4.4 & 4.5 & 4.6 & 4.7\end{array}$ \\ $\mathrm{Vsv}, \mathrm{km} / \mathrm{sec}$}




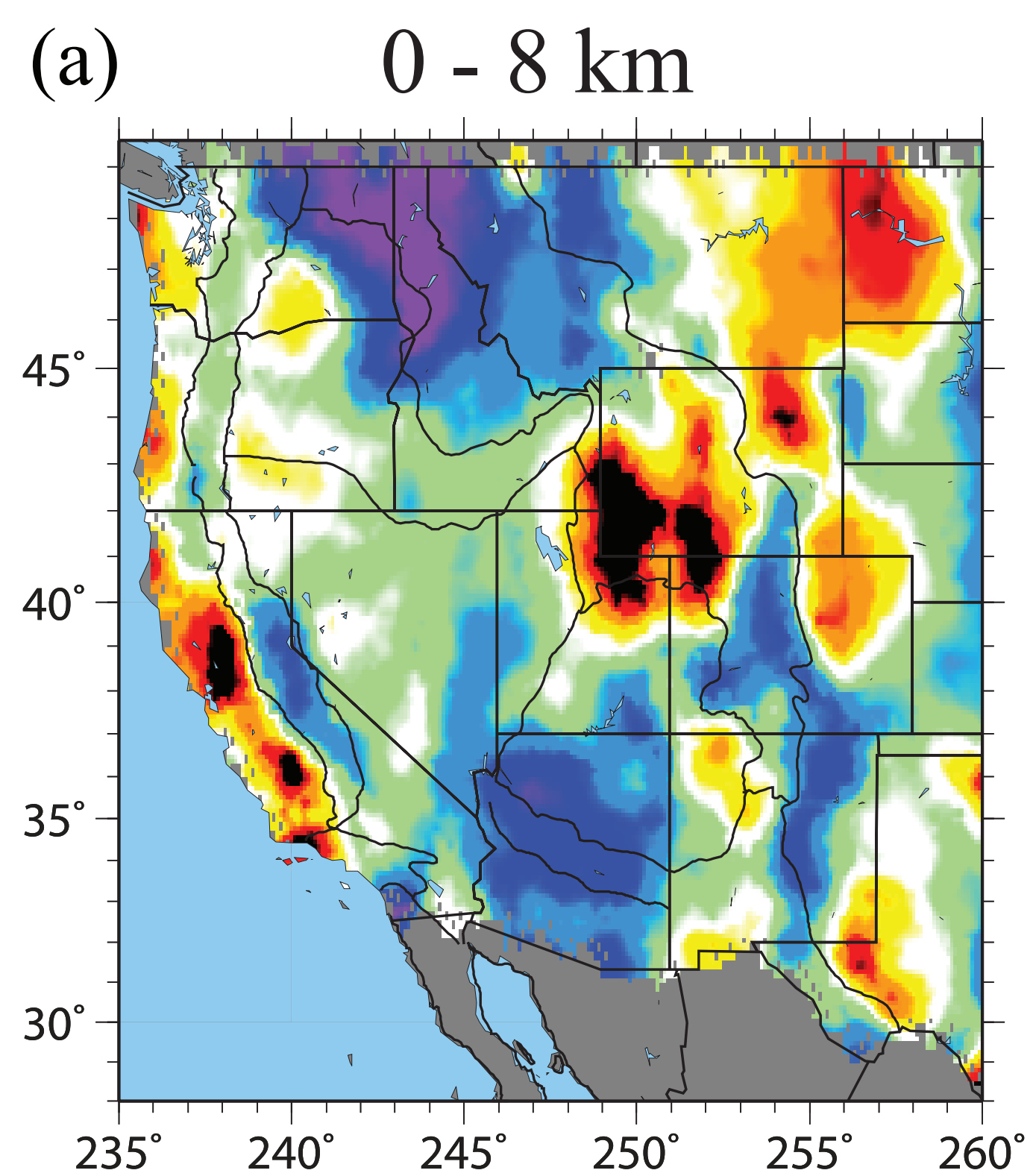

(b) lower-crust
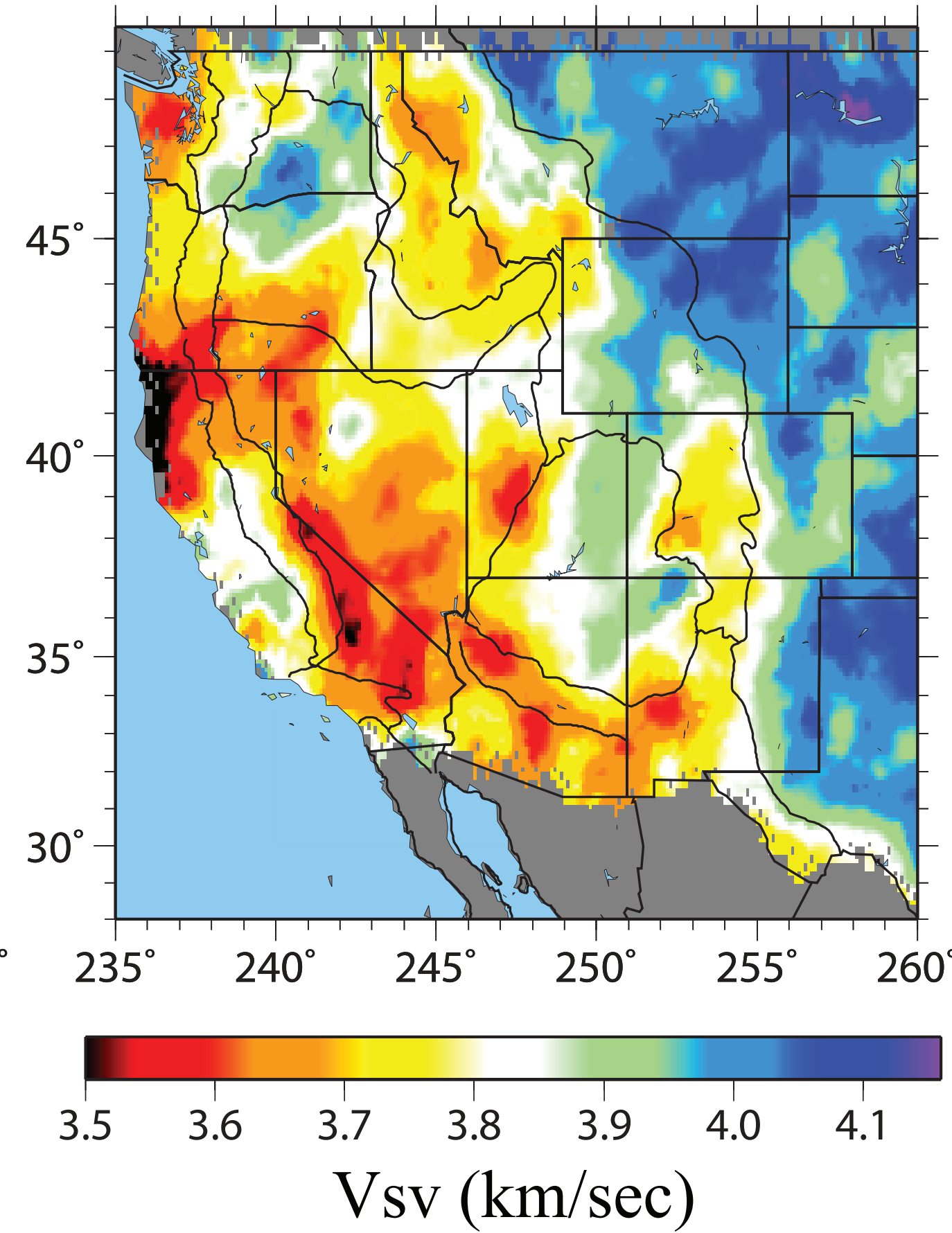
(c)
$60 \mathrm{~km}$

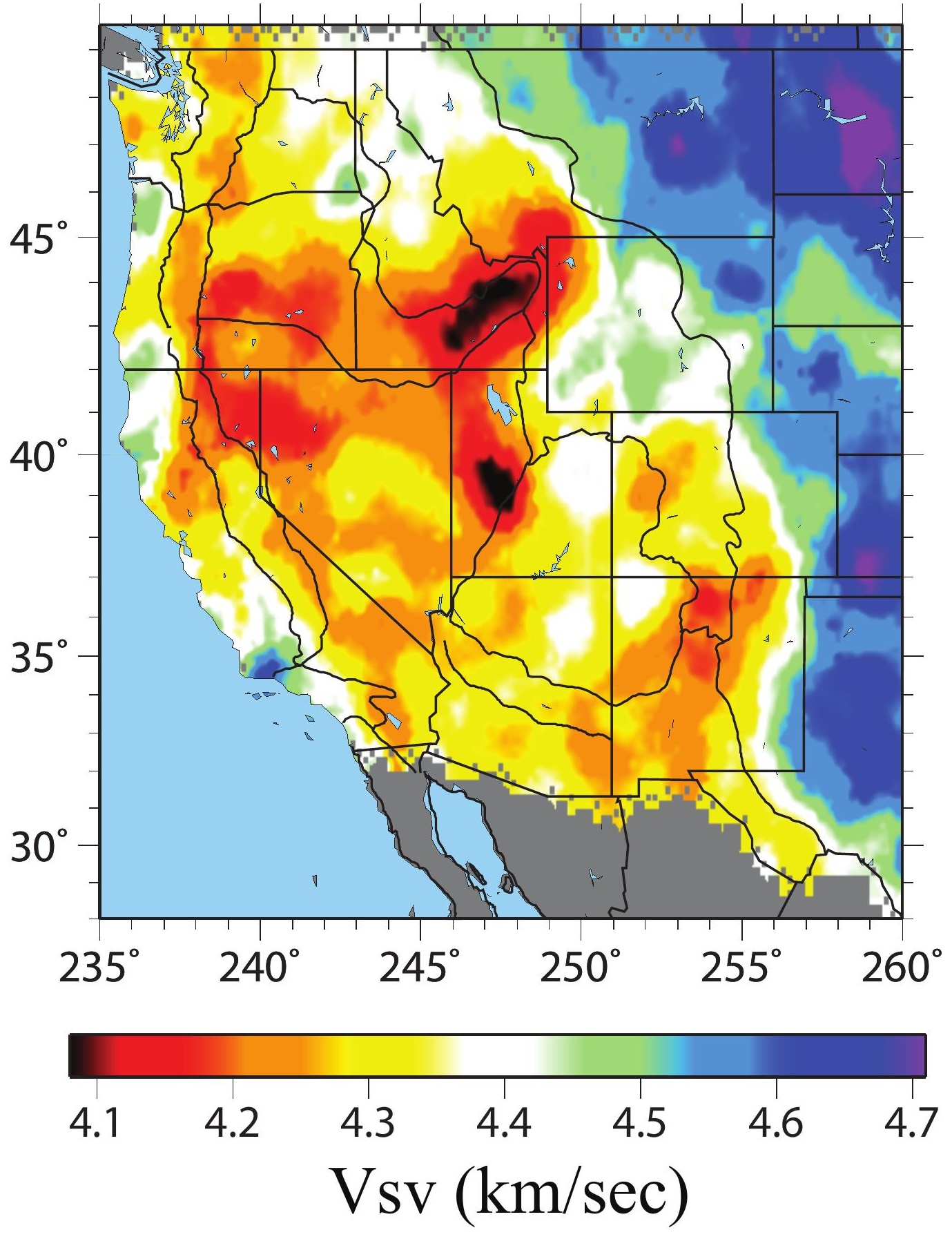


$0-8 \mathrm{~km}$

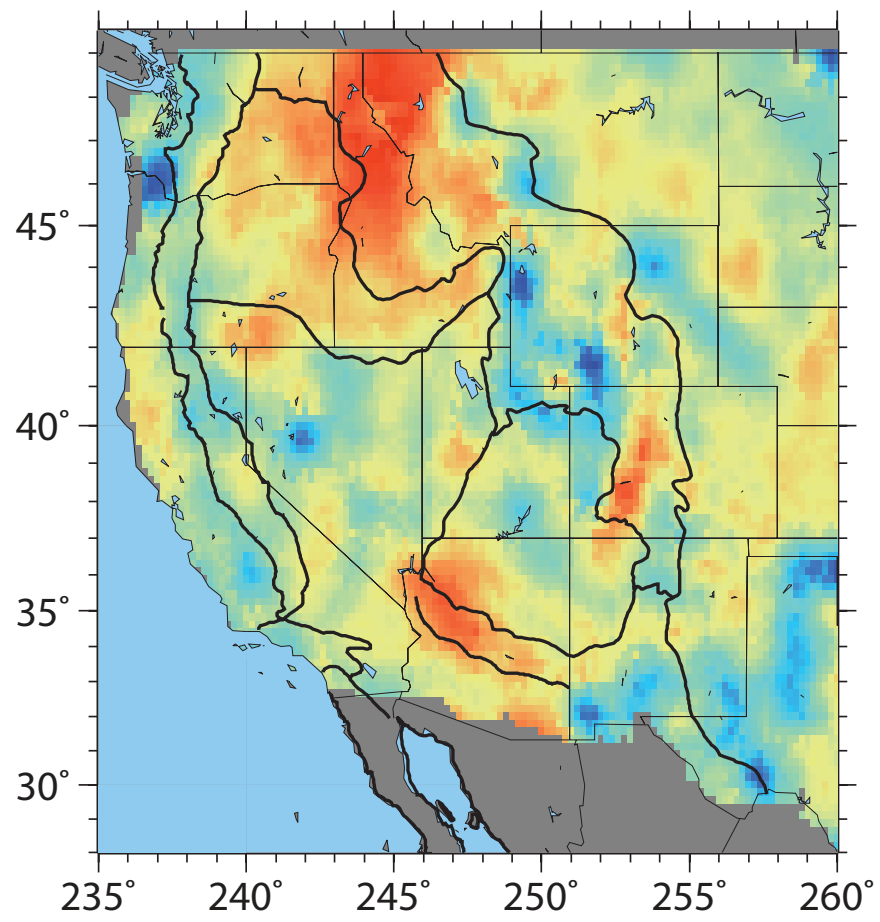

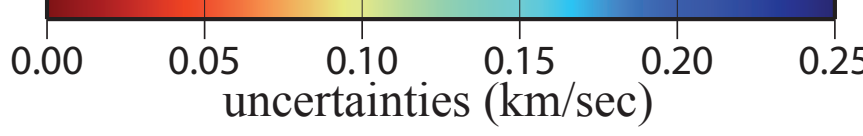

$60 \mathrm{~km}$

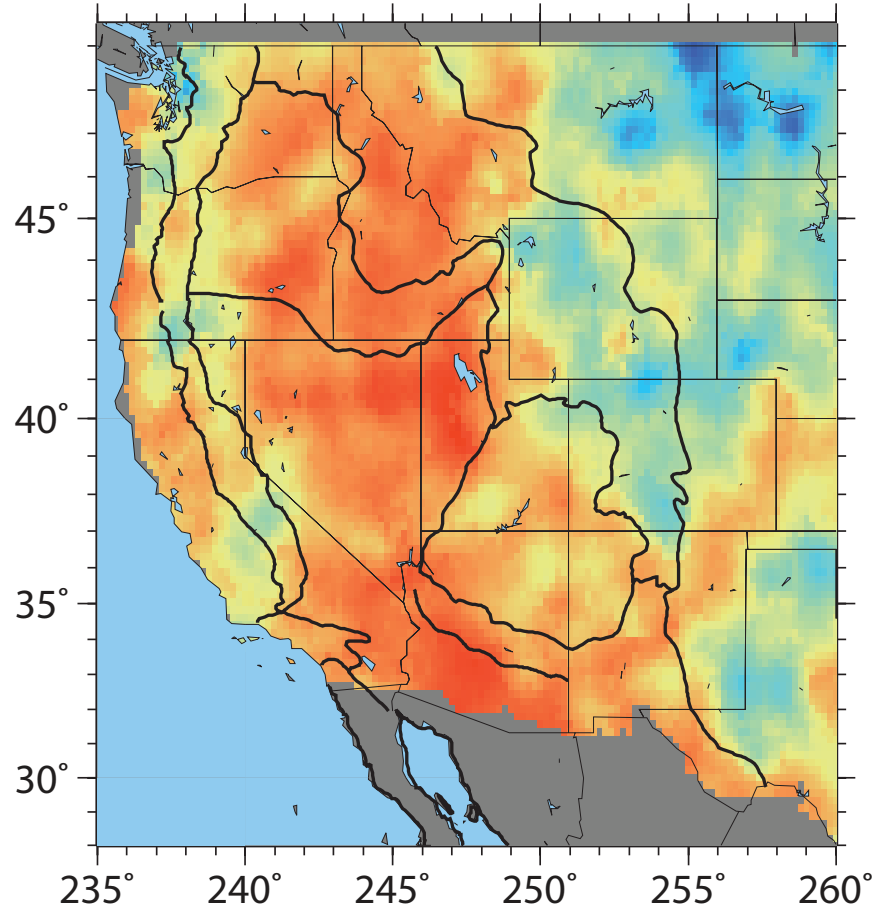

lower crust

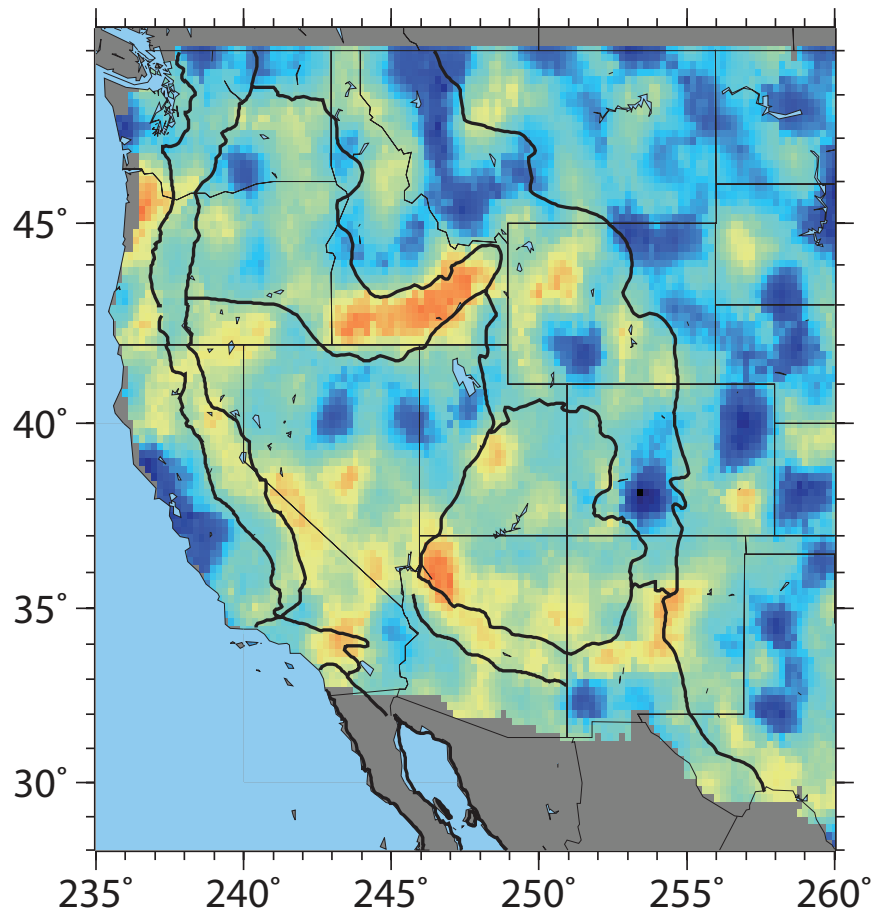

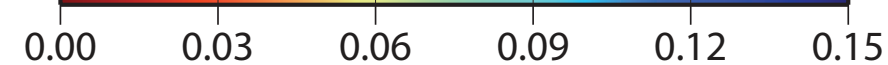
uncertainties $(\mathrm{km} / \mathrm{sec})$

$120 \mathrm{~km}$

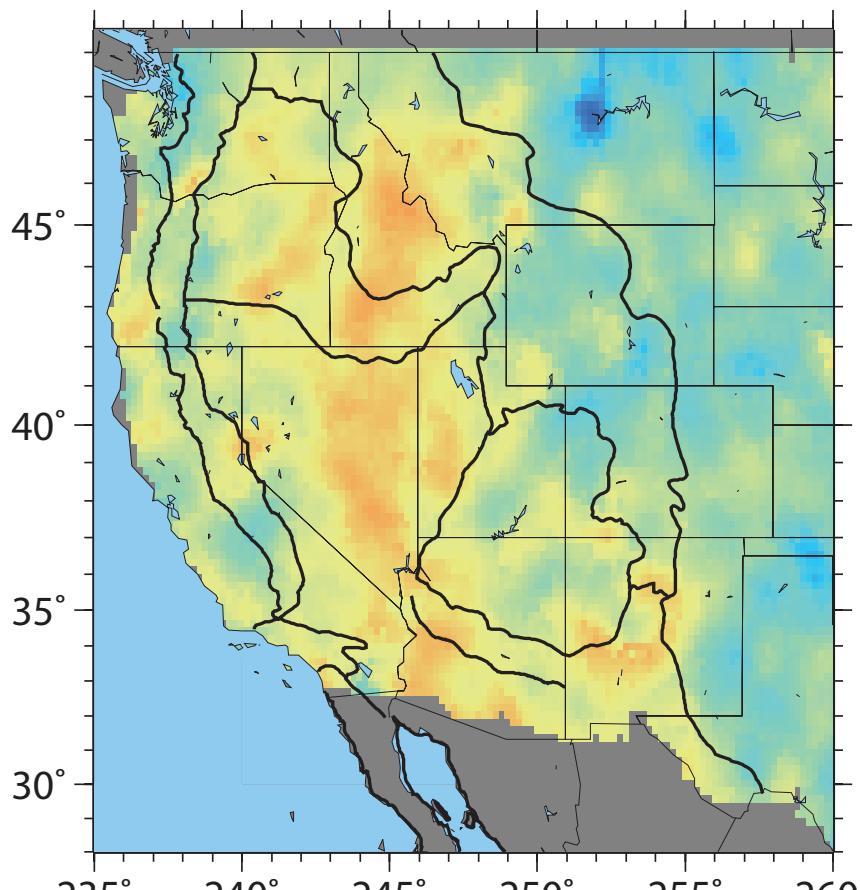

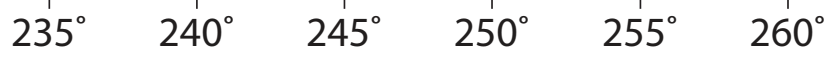

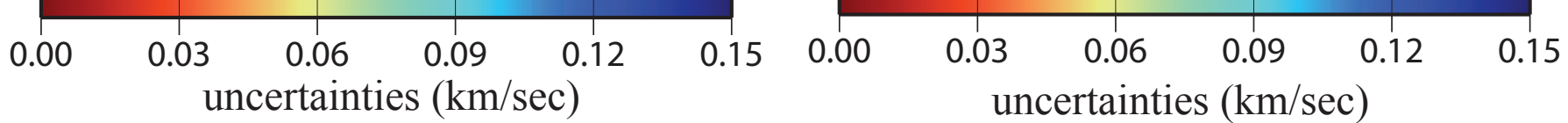


(a)

Crustal thickness

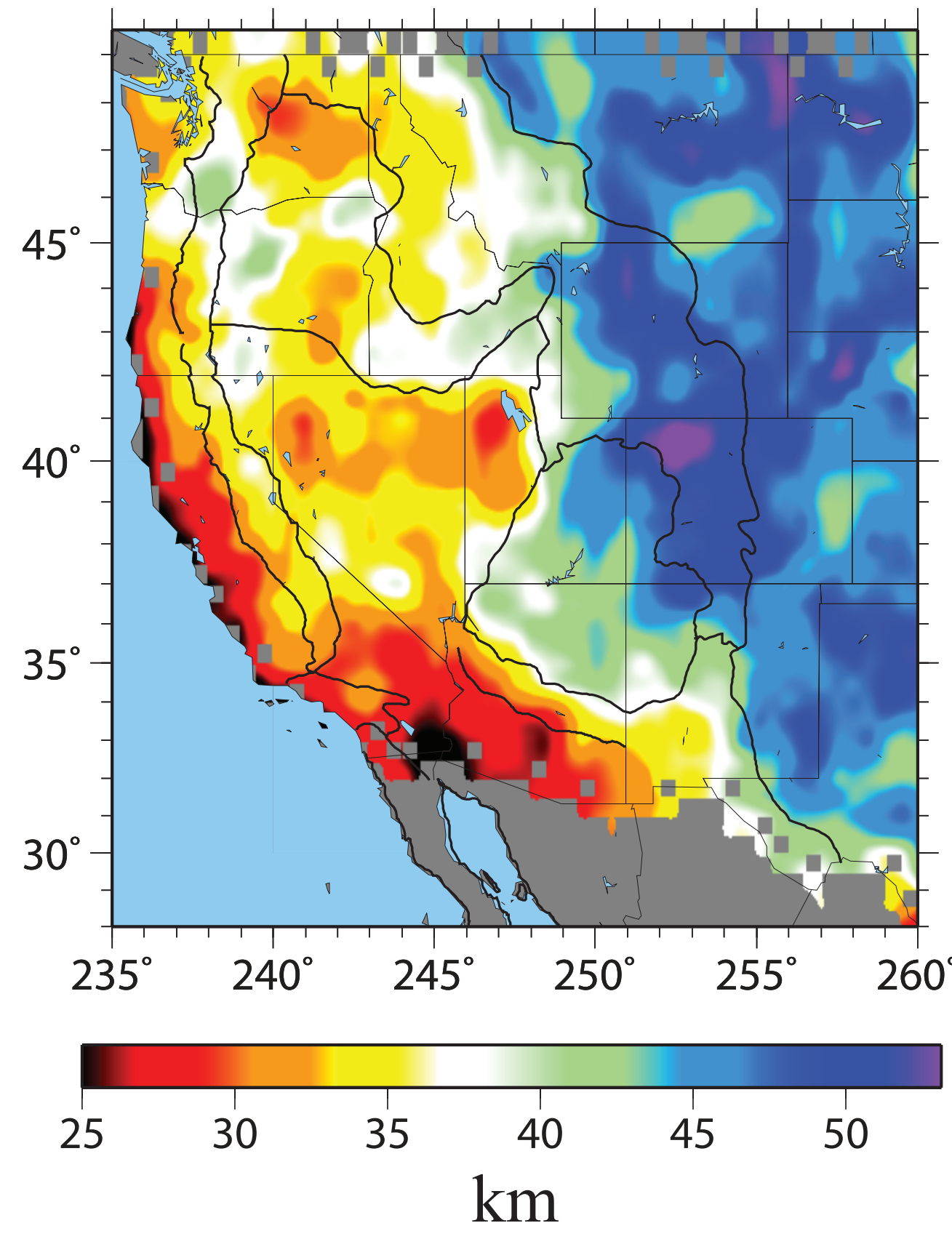

(b)

Vsv contrast across Moho

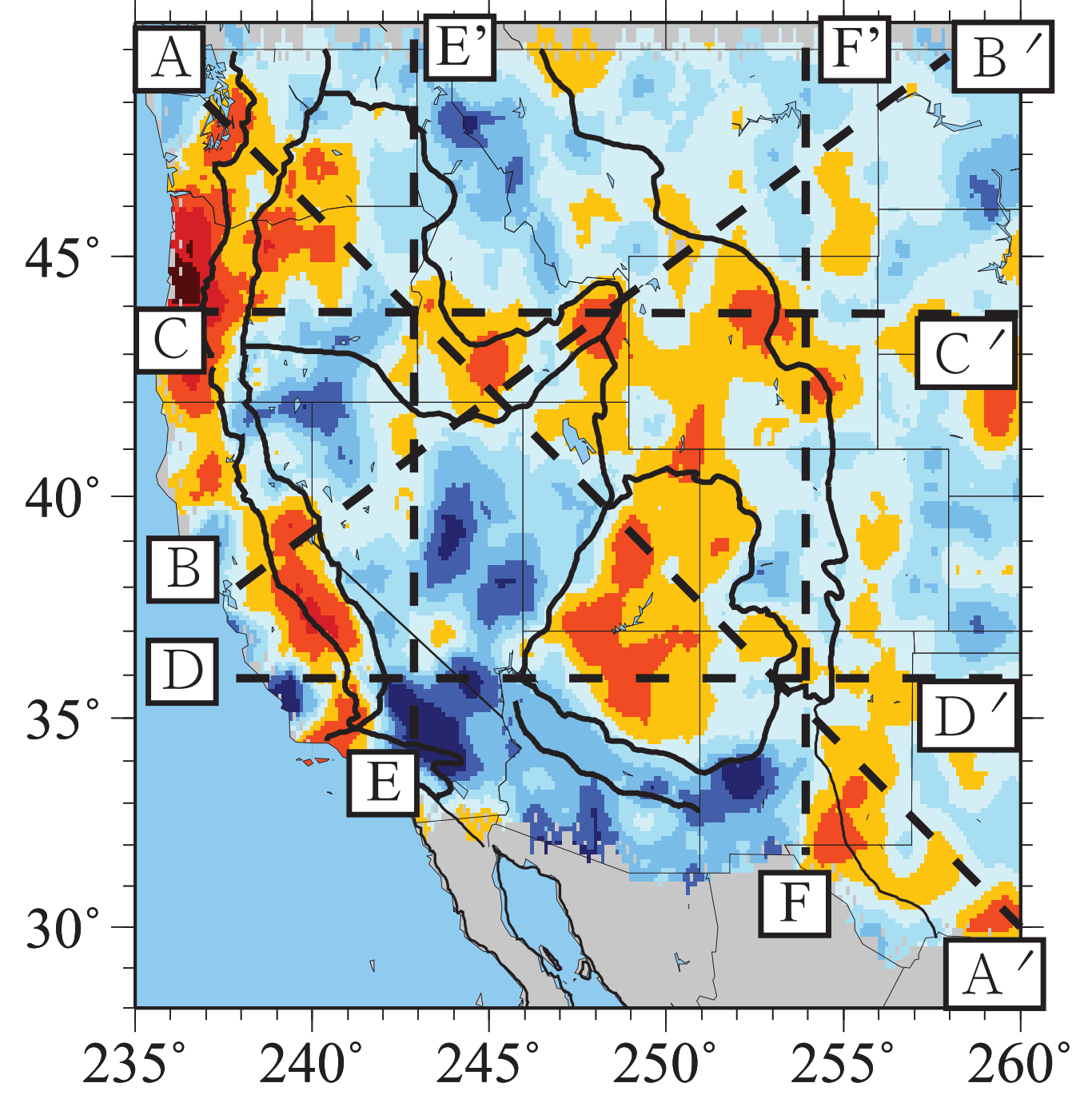

$\begin{array}{llllllll}0.1 & 0.2 & 0.3 & 0.4 & 0.5 & 0.6 & 0.7 & 0.8\end{array}$ $\mathrm{km} / \mathrm{sec}$ (c)

Fig 9

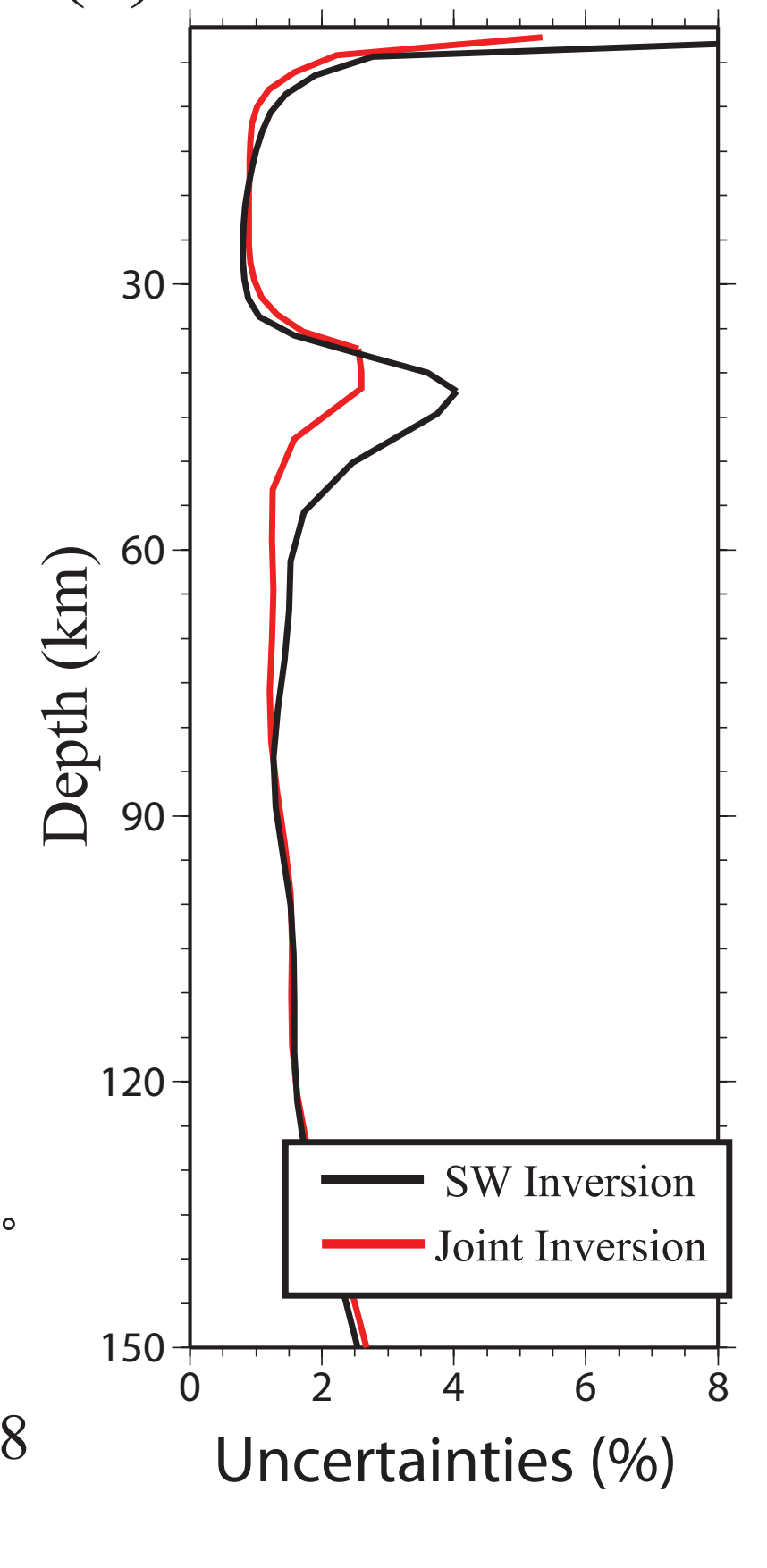




\section{Fig 10}

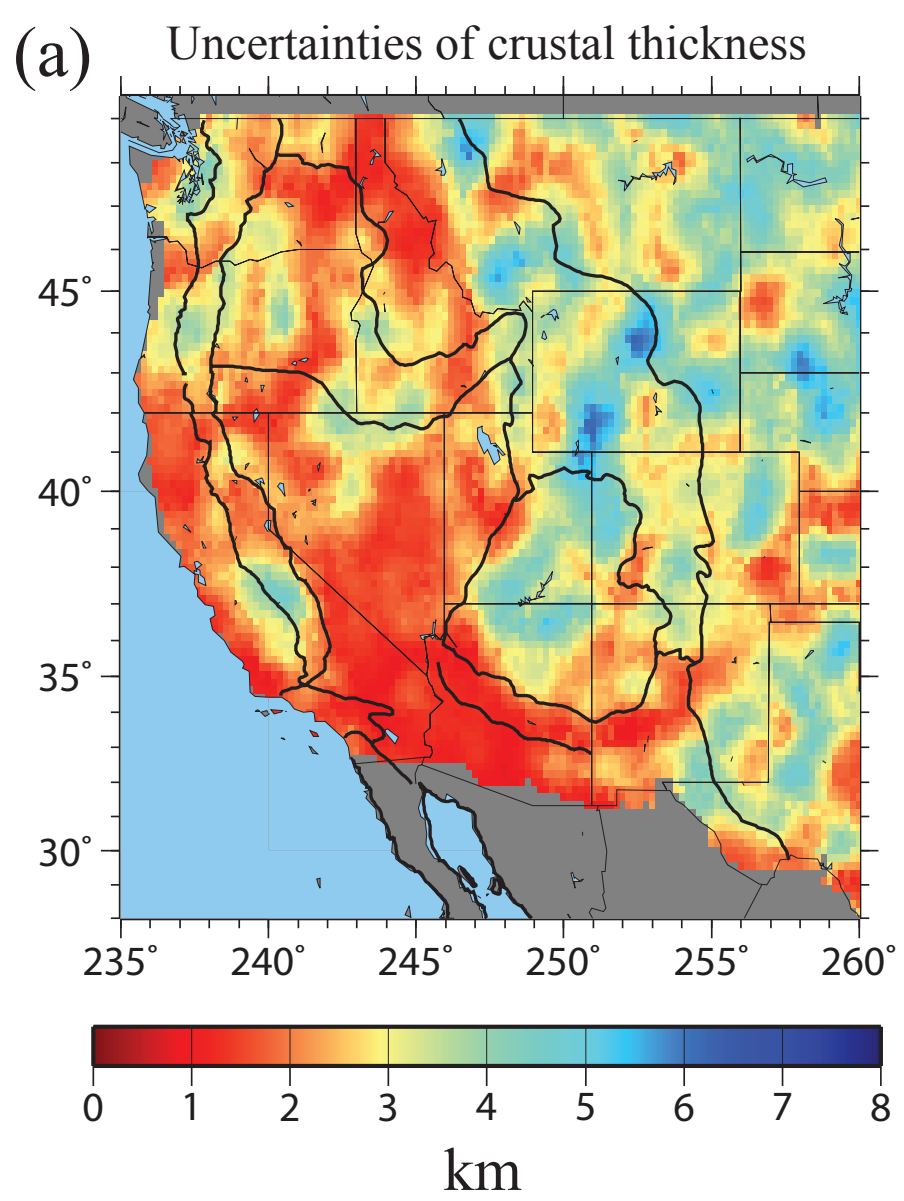

(b) Uncertainties of Vsv contrast

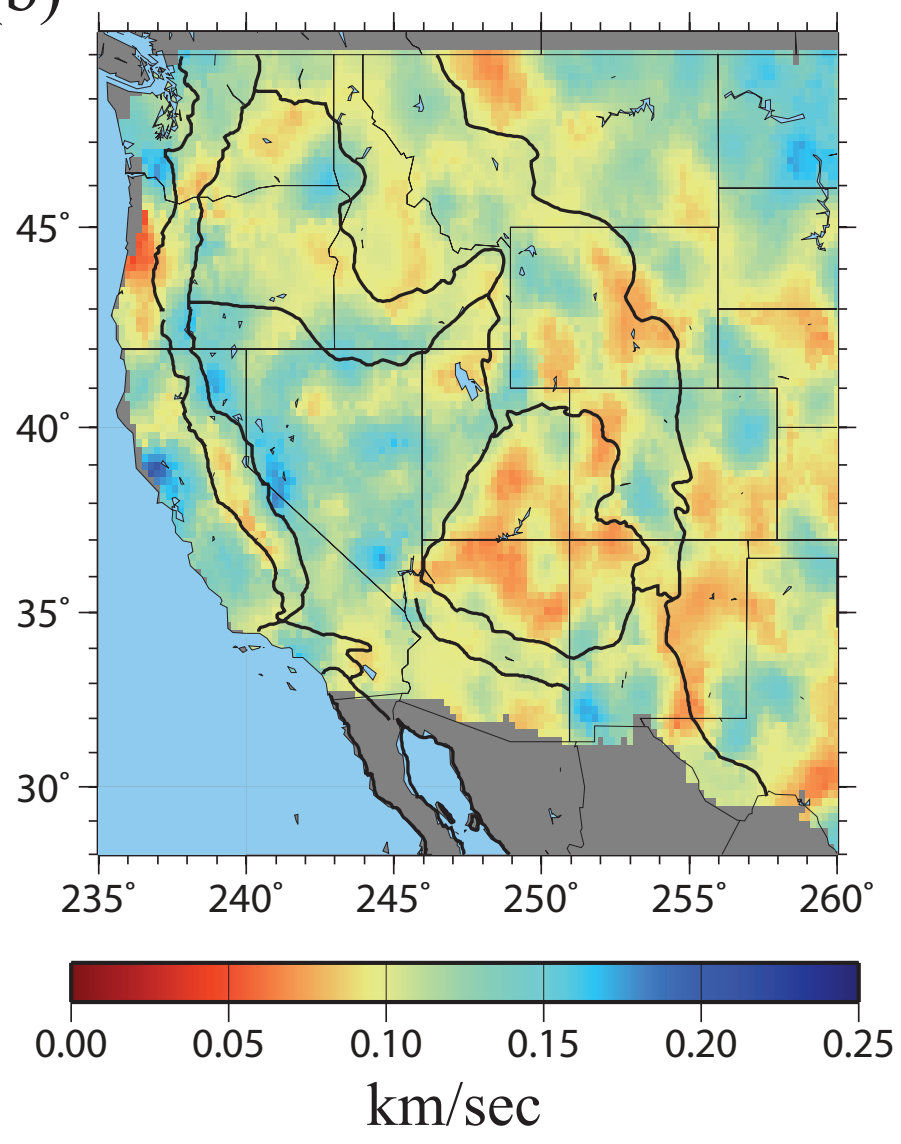



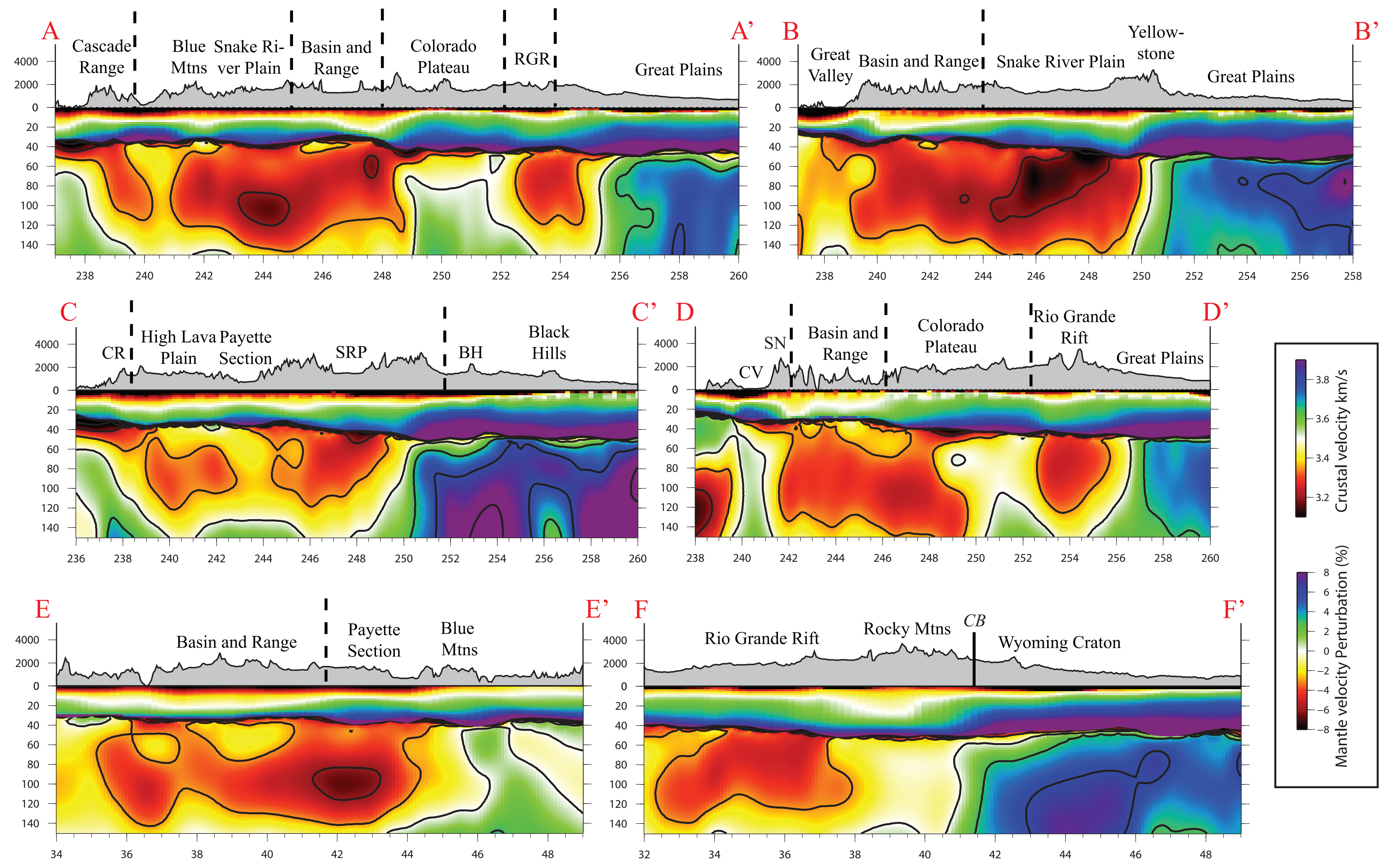